\title{
Autonomía Local, Régimen Local Básico y Reformas Estatutarias
}

\author{
Luciano Parejo Alfonso \\ Catedrático de Derecho Administrativo \\ Universidad Carlos III de Madrid
}

Sumario: I. INTRODUCCIÓN.-II. LA AUTONOMÍA LOCAL Y EL DESARROLLO CONSTITUCIONAL: LAS COMPETENCIAS LEGISLATIVAS EN LA MATERIA, EN ESPECIAL LA ESTATAL PARA EL DICTADO DE LA LEGISLACIÓN BÁSICA. 1. El principio de autonomía y la organización territorial del Estado. 2. La autonomía local; su doble función constitucional como principio y garantía. 3. La peculiaridad de la ultimación de la organización territorial del Estado en su instancia basal: la autonomía local como una de las materias del sistema de distribución de competencias entre las dos instancias territoriales superiores del Estado. 4. El «régimen local» y la asignación de la competencia legislativa en la materia. 4.1. La situación hasta la reforma estatutaria en curso. 4.2. El cuestionamiento de la situación establecida. 4.3. La situación resultante de las reformas estatutarias. 4.3.1. Los nuevos Estatutos de Autonomía con menor pretensión de «interiorización». 4.3.1.1. Análisis. 4.3.1.2. Conclusiones. 4.3.2. Los nuevos Estatutos con mayor pretensión de «interiorización». 4.3.2.1. Análisis. 4.3.2.2. Conclusiones. 5. La determinación constitucional del título competencial del Estado en sentido estricto en materia de régimen local. - III. EL CONTENIDO Y ALCANCE DE LA LEGISLACIÓN BÁSICA DE RÉGIMEN LOCAL. 1. Consideraciones generales. 2. Contenido mínimo de unas eventuales nuevas bases del régimen local. 2.1. Ámbito subjetivo y objetivo del régimen local básico. 2.2. Organización de Municipios y Provincias. 2.3. Competencias municipales y provinciales. 2.4. Régimen de la actividad ad extra de los entes necesarios. 3 . Alcance de unas eventuales nuevas bases del régimen local.

\section{INTRODUCCIÓN}

Frustrada en la anterior legislatura la iniciativa legislativa dirigida a la sustitución de la vigente Ley 7/1985, de 2 de abril, reguladora de las bases de régimen local, por una Ley de nuevo cuño relativa al gobierno y la administración locales, el Gobierno parece haberla abandonado siquiera provisionalmente, aunque, en algún momento de esta legislatura y una vez avanzado el proceso de reforma de los Estatutos de Autonomía desencadenado por el de Cataluña, alguna de sus actuaciones pudo interpretarse en el sentido de retomarla precisamente para la aprobación de un texto referido ahora al «Gobierno Local».

A la vista de los nuevos Estatutos de Autonomía en vigor - especialmente el catalán y el andaluz, pero también el valenciano - y, por tanto, del actual y resultante bloque de la constitucionalidad, la posibilidad de la novación de la legislación básica de régimen local de 1985 suscita la cuestión de su viabilidad y alcance legitimo y actualiza, así, el interés por la pieza basal de la organización territorial del Estado. 


\section{LA AUTONOMÍA LOCAL Y EL DESARROLLO CONSTITUCIONAL: LAS COMPETENCIAS LEGISLATIVAS EN LA MATERIA, EN ESPECIAL LA ESTATAL PARA EL DICTADO DE LA LEGISLACIÓN BÁSICA}

\section{El principio de autonomía y la organización territorial del Estado}

Desde el punto de vista sistemático, la Constitución (en adelante CE) proclama la autonomía local significativamente con ocasión del establecimiento de los principios generales (capítulo I) de la organización territorial del Estado (título VIII), a los que siguen (agotando el contenido del título) las disposiciones relativas a la «Administración Local» (capítulo II) y las «Comunidades Autónomas» (capítulo III). Se trata, pues, de una determinación constitucional de carácter organizativo inserta en un título asimismo organizativo, que forma parte de la igualmente parte organizativa del texto constitucional que comprende, cuando menos, desde el título II hasta el IX, ambos inclusive. Y de una determinación, por tanto, «constituyente» en el sentido más estricto del término, cabalmente en el que expresa el artículo 1.1 de la norma fundamental cuando dice que España se constituye (id est: se organiza, por decisión soberana del pueblo español) en un Estado social y democrático de Derecho.

La redacción del artículo 137 CE es concluyente al respecto, pues comienza justamente afirmando que el Estado así constituido «se organiza territorialmente».

Pero así como en los títulos II a VII y IX el constituyente - presuponiendo esa decisión de articulación territorial- organiza directamente, en lo fundamental, las instituciones generales del Estado, opera de forma inversa en el título VIII cuando de las instituciones territoriales de poder público se trata. Limitándose a una más o menos escueta regulación, entrega la concreción de la organización territorial (entendida como aquélla en que se expresan las referidas instituciones territoriales), en lo fundamental, al proceso de desarrollo constitucional, si bien en términos diversos para cada una de las dos instancias en que se descompone aquella organización: las Comunidades Autónomas y la Administración Local.

En el primer caso ese desarrollo se reserva a un específico tipo de norma (Ley orgánica elaborada y aprobada por un procedimiento peculiar) destinado a articular la disposición sobre si misma reconocida a la correspondiente colectividad (en ejercicio del derecho a la autonomía de que hablan los arts. 2 y 143.1 CE). En el segundo no hay tal, quedando encomendado el desarrollo constitucional genéricamente a la Ley sin mayor determinación (salvo alguna referencia para aspecto muy concreto a la Ley orgánica; véanse los arts. 140, 141 y $142 \mathrm{CE})$. 
Aunque ello sea así, el entero desarrollo constitucional de la completa organización territorial debe producirse conforme a un principio general único formulado en el artículo 137 CE: todas las entidades de la organización territorial del Estado «...gozan de autonomía para la gestión de sus respectivos intereses». De ello se sigue:

1. $\quad$ La autonomía de las entidades integrantes de la Administración local es un principio estructural de la organización territorial del Estado.

Esta es la razón por la que la doctrina constitucional tiene establecido (desde pronunciamientos bien tempranos: SsTC 32/1981, fto. Jur. 5; y 27/1987, de 27 de febrero) que: «...a través de la garantía constitucional de la autonomía local se configura un modelo de Estado». Lo que no puede significar otra cosa que la pertenencia de la autonomía local, desde y por sí misma y en cuanto alusiva a una de las instancias necesarias de la organización territorial del Estado social y democrático de Derecho constituido, a los elementos definitorios de tal Estado.

2. $\quad$ La autonomía se predica de las entidades (organización del poder público) para la gestión de sus intereses, lo que vale decir de los de las colectividades que institucionalizan. Tiene así, en cuanto principio, una doble dimensión cuyos elementos, aunque diferenciables, están inescindiblemente unidos, pues la organización es del poder público y la existencia de éste sólo puede justificarse en la gestión de intereses públicos a través de potestades ejercidas en ámbitos competenciales concretos. Dicho de otro modo: están necesariamente imbricados (no pudiendo existir el uno sin el otro) en la medida en que traducen aspectos de un mismo y único proceso de organización.

\section{La autonomía local; su doble función constitucional como principio y garantía}

La doble dimensión del principio de autonomía local no es una peculiaridad de ésta, puesto que es propia también de la autonomía de las Comunidades Autónomas (donde se vuelve a manifestar la pertenencia a la estructura de la entera organización territorial del principio general de autonomía).

Pero este carácter común contribuye a clarificarla, puesto que la más densa regulación directa constitucional de su aplicación a las Comunidades Autónomas proporciona datos decisivos sobre sus elementos. Nótese, en efecto, que conforme al artículo $147 \mathrm{CE}$ la norma estatutaria en que se concreta, en sede de desarrollo constitucional, el llamado «proceso autonómico» tiene dos componentes esenciales, ambos de carácter organizativo: i) la articulación de la instancia autonómica (denominación, delimitación territorial y determinación de sus instituciones propias); y ii) la dotación de dicha instancia con competencias. 
Lo mismo sucede en el caso de la autonomía local, como se deduce, de un lado, de los artículos 140 y $141 \mathrm{CE}$ (en los que se predetermina constitucionalmente la articulación de las entidades integrantes de la Administración local), y, de otro lado, el artículo $142 \mathrm{CE}$ (en el que se sienta el principio de suficiencia financiera justamente al servicio de la dotación competencial o «...desempeño de las funciones que la Ley atribuye a las corporaciones respectivas...»).

Esta doble faceta del principio de autonomía local determina y, al propio tiempo, explica su también doble función en la dirección del desarrollo constitucional. Si de una parte se ofrece, cuando de la articulación de las entidades locales se trata, como garantía (de su existencia y características esenciales, especialmente de la cualidad de gestión bajo la propia responsabilidad), de otra parte aparece como principio del sistema de distribución territorial de competencias. Se trata, pues, de manifestaciones de un mismo principio cuyo juego complementario requiere la efectividad de la autonomía local querida por el texto constitucional y en modo alguno - como pudiera deducirse de algún planteamiento doctrinal que ha visto en la segunda una superación de las supuestas insuficiencias de la primerade interpretaciones distintas y alternativas del referido principio.

Según resume y clarifica la STC 240/2006, de 20 de julio [fto. jur. 8] la doctrina previamente sentada, entre otras, en las SsTC 4/1981; 32/1981; 27/1987; 40/1998; 213/1988; 259/1988; 170/1989; 214/1989; 109/1998; 159/200; 51/2004; у 252/2005):

a) En tanto que garantía:

- La autonomía local consagrada en el art. 137 CE (con el complemento de los arts. 140 y $141 \mathrm{CE}$ ) alude a la preservación de una institución en términos recognoscibles para la imagen que de la misma tiene la conciencia social de cada tiempo y lugar y, por tanto, consiste en una protección constitucional del contenido mínimo de aquélla, constituido por los elementos esenciales o núcleo primario del autogobierno de los entes locales territoriales; núcleo que, por ello, debe necesariamente ser respetado por el legislador (estatal o autonómico, general o sectorial) para que dichas Administraciones sean reconocibles en tanto que entes dotados de autogobierno.

- Por ello, sólo puede reputarse desconocida - pero, al mismo tiempo, debe serlo- cuando la institución es limitada de tal modo que se la priva prácticamente de sus posibilidades de existencia real como institución para convertirse en un simple nombre. Más allá de su contenido mínimo protegido, la autonomía local es un concepto jurídico de contenido legal, que permite configuraciones legales diversas, válidas en cuanto respeten la garantía institucional.

- De ahí, que la concreta configuración institucional de la autonomía local corresponda al legislador, incluyendo la especificación del ámbito 
material de competencias de la entidad local, así como las fórmulas o instrumentos de relación con otras entidades públicas y el sistema de controles de legalidad constitucionalmente legítimos. Y ello, sin más límite que el del reducto indispensable o núcleo esencial de la institución. En la medida en que el texto constitucional no ha predeterminado el contenido concreto de la autonomía local, el legislador constitucionalmente habilitado para regular materias de las que sea razonable afirmar que formen parte de ese núcleo indisponible podrá así, ciertamente, ejercer en uno u otro sentido su libertad inicial de configuración, pero nunca de manera que establezca un contenido de la autonomía local incompatible con el marco general perfilado en los arts. 137, 140 y $141 \mathrm{CE}$ (so pena de infracción de la garantía institucional).

- De lo que resulta que el núcleo garantizado viene a equivaler al contenido prescriptivo de los expresados artículos constitucionales, tanto del expreso, como del ímplícito en ellos o deducible directamente de los mismos (en su caso, en conexión con otros preceptos constitucionales).

b) Y, en tanto que principio del sistema de distribución territorial de competencias la autonomía local implica: i) positivamente, el derecho de la comunidad local a participar a través de órganos propios en el gobierno y administración de cuantos asuntos le atañen (graduándose la intensidad de la participación en función de la relación existente entre los intereses locales y supralocales dentro de tales asuntos o materias); derecho aquél que debe ser respetado y realizado por el legislador que concrete la configuración de la institución local y participación ésta para cuyo ejercicio los órganos representativos de la comunidad local han de estar dotados de las potestades y las competencias sin las que ninguna actuación autónoma es posible [se trata, como advierte el propio Tribunal Constitucional, de una noción ésta muy similar a la acogida por la Carta Europea de la Autonomía Local de 1985 en su artículo 3]; y ii) negativamente, veda al legislador toda regulación de la capacidad decisoria de los entes locales respecto de las materias de su interés que se sitúe por debajo de ese umbral mínimo que les garantiza su participación efectiva en los asuntos que les atañen y, por consiguiente, su existencia como reales instituciones de autogobierno.

Aunque la doctrina del Tribunal Constitucional no lo haya destacado así expresamente, pero puede inferirse lógicamente de ella, la vertiente competencial que asegura el principio de autonomía local coincide también con la establecida - bajo la rúbrica «alcance de la autonomía local - por el artículo 4.1 de la Carta Europea de la Autonomía local, cuando dice que las competencias básicas de las entidades locales vienen fijadas por la Constitución o por la Ley, sin perjuicio de la atribución a aquéllas de competencias para fines específicos de conformidad con la Ley. Lo que significa que las entidades locales deben contar en todo caso con un elenco de competencias propias, un espacio decisional propio en que pueda realizarse el autogobierno garantizado (correlato indispensable y necesario de éste). 


\section{La peculiaridad de la ultimación de la organización territorial del Estado en su instancia basal: la autonomía local como una de las materias del sistema de distribución de competencias entre las dos instancias territoriales superiores del Estado}

La menor densidad de la regulación del texto constitucional en el caso de la autonomía local respecto de la de las Comunidades Autónomas explica el hecho decisivo de la inevitablemente mayor confusión, en el caso de la primera y en el desarrollo constitucional, de los elementos constitutivos de la doble dimensión expuesta.

La predeterminación constitucional más precisa y diferenciada, en efecto y para el llamado «proceso autonómico», de la «construcción» institucional de las Comunidades Autónomas y de la dotación a éstas con competencias (a partir, en cuanto a esto último, de un formalmente doble listado constitucional de materias-competencias), permite el juego complementario de ambos aspectos sin merma de su respectiva identidad gracias a la desembocadura del aludido proceso en una norma institucional básica de cada Comunidad Autónoma expresiva del ejercicio de un derecho constitucional colectivo: el derecho a la autonomía. Porque esto permite, a su vez, que el entero proceso autonómico, aún perteneciendo al desarrollo constitucional, se mantenga estrictamente dentro de la lógica propia de la continuación de la organización del Estado para su ultimación en sede de desarrollo constitucional, es decir, se siga ofreciendo y percibiendo como acto organizativo «constitutivo» de la correspondiente Comunidad Autónoma. Lo que, de un lado, trae causa de la novedad - no obstante concretos precedentes históricos - de la pieza autonómica de la organización territorial del Estado y, de otro lado, sea dicho de paso, explica que dicho acto rigurosamente constitutivo se adscriba al llamado «bloque de la constitucionalidad» no precisamente por prescripción constitucional, sino por doctrina constitucional establecida a partir del artículo 28.1 de la Ley orgánica 2/1979, de 3 de octubre, del Tribunal Constitucional.

Nada de ello sucede en el caso de la autonomía local por tres razones principales:

1. ${ }^{\mathrm{a}}$ La ausencia, en el caso de la instancia local y por inexistencia de un sujeto colectivo legitimado para ejercer derecho constitucional alguno para el acceso a y el ejercicio de la autonomía, de «proceso autonómico» constitutivo de la instancia local, ya que - para el diseño de la organización territorial del Estado - el constituyente se limitó a reconocer y asumir una realidad social previa (con relevancia jurídico-política) de larga tradición para incorporarla a la organización territorial en calidad de pieza basal necesaria de la misma (único momento éste constitutivo de su decisión organizativa). De ahí justamente la dimensión garantizadora de tal decisión; dimensión referida, así, a una institución existente y poseedora, por tanto, de una imagen asentada en la conciencia colectiva susceptible de protección y preservación. 
2. ${ }^{a} \quad$ La condición de Administración pública, y sólo de Administración pública, de la institución-poder público local, la cual - al no permitirle la disposición de la potestad legislativa - la coloca enteramente «en el marco de la Ley», lo que vale decir - dado el reparto exhaustivo de esta potestad para el entero universo de las materias o los objetos posibles - de las Leyes emanadas de las instancias territoriales superiores.

3. ${ }^{\text {a }}$ La consecuente difuminación del indudable carácter organizativo de la concreción, en sede de desarrollo constitucional, de la autonomía local como continuación en aquella sede y por otros medios de la definición, para su ultimación, de la organización territorial del Estado. Difuminación ésta derivada del hecho clave de que la institución local no aparece en ella como sujeto y si únicamente como objeto garantizado frente a la acción configuradora de otras instancias de poder público ya constituido.

Aunque esto sea indudablemente así, no puede olvidarse el dato fundamental de que no por ello la expresada concreción legal de la autonomía local deja de ser, enteramente, ejercicio del poder o potestad de organización. Pues sigue siendo parte de la «reflexión del Estado sobre si mismo», es decir, su estructura, organización y funcionamiento, de que habla la doctrina del Tribunal Constitucional.

Estas características diferenciales de la autonomía local son la causa de que - en su caso y a diferencia de lo que sucede en el de las Comunidades Autónomas, en el que el proceso autonómico se ofrece todo él, cualquiera que sea su contenido (organización y funcionamiento o dotación competencial), como ejercicio del genérico poder de organización - la normativa institucional que la concreta y realiza se transmute, ocultando su condición de producto desde luego de dicho poder (ya constituido) de organización, en una materia más de las que son objeto del sistema constitucional de distribución territorial de competencias entre las dos instancias territoriales superiores. Es esta transmutación la que, al velar la verdadera naturaleza organizativa de la decisión o conjunto de decisiones englobadas en la determinación de la referida normativa institucional e impedir, así, la contemplación del «régimen local» - al igual que sucede con la de la norma institucional básica de cada Comunidad Autónoma- como acto organizativo único, es decir y en términos procesales, determinante de la continencia de dicho régimen, implica el riesgo de la fragmentación indebida de la normativa institucional local en función de la lógica de la acción legislativa de las instancias superiores, es decir, de la interpretación del sistema de distribución de competencias entre ellas.

En definitiva: el régimen local es una materia de perfil singular que integra el objeto de una específica legislación, cuya especificidad - por razón de la peculiaridad de la materia constitutiva de su objeto: la concreción del estatuto institucional de la instancia local - determina la especificidad, a su vez, de la asignación de la competencia para su establecimiento, que consiste en su inclusión del poder constituido de organización en términos que permitan la ulterior 
continuación de su ejercicio por la propia instancia local actuando la potestad de autoorganización inscrita en la autonomía local garantizada constitucionalmente $^{1}$. Motivo por el cual la legislación de régimen local es esencialmente ejercicio del poder (constituido) de organización para la ultimación - por lo que hace a su pieza basal-de la organización territorial del Estado.

\section{El «régimen local» y la asignación de la competencia legislativa en la materia}

\subsection{La situación hasta la reforma estatutaria en curso}

La reticencia del Tribunal Constitucional a reconocer determinaciones constitucionales de carácter o alcance competencial (cuando de la distribución territorial de éstas se trata) fuera de los preceptos que específicamente tienen por objeto tal distribución, justifica la concentración en los artículos 148 y 149 CE a la hora de la determinación de la materia «régimen local» y los términos de la asignación de la competencia legislativa en ella. Porque entre el elenco de «materias» enunciadas en el artículo 148.1 CE figura efectivamente, como segunda, el «régimen local».

Esta previsión constitucional implica cuando menos dos cosas que se suelen descuidar, si no marginar, en la interpretación del orden constitucional:

1. La contemplación expresa por el constituyente del régimen local como el objeto de una precisa legislación y, por tanto, de un específico complejo de decisiones organizativas necesariamente articuladas entre sí para integrar la regulación institucional completa y coherente de la instancia territorial local en desarrollo del principio-garantía de su autonomía.

2. La formulación de su previsión expresa como materia en términos que presuponen que el Estado stricto sensu tiene competencia en la materia.

Lo que es de todo punto lógico, si se considera, como recuerda la STC 214/1989, de 21 de diciembre, que han dejado dicho las SsTC 32/1981, de 28 de julio, y 27/1987, de 27 de febrero, que — dado que a través de la garantía constitucional de la autonomía local se configura un modelo de Estado y que esa garantía es de carácter general - no puede dejarse a la interpretación de las Comunidades Autónomas el derecho de las comunidades locales a su autonomía y corresponde así a los órganos centrales del Estado la fijación de principios o criterios básicos en esta materia (en los aspectos institucionales y competenciales), de aplicación en todo el territorio estatal.

\footnotetext{
1 La jurisprudencia del Tribunal Constitucional sobre este extremo es clara. Véanse las SsTC 35/1982, de 14 de junio; 76/1983, de 5 de agosto; 157/1985, de 15 de noviembre; 165/1986, de 18 de diciembre; 227/1988, de 29 de noviembre; 214/1989, de 21 de diciembre (especialmente importante para las entidades locales); 204/1992, de 26 de noviembre; 50/1999, de 6 de abril; y 251/2006, de 25 de julio.
} 
No es constitucionalmente legítima, pues, la colocación de la concreción legislativa de la autonomía local fuera del esquema de distribución territorial de competencias que resulta de los artículos 148.1 y 149.1 CE para entenderla comprendida entre las no expresamente reservadas al Estado stricto sensu a las que se refiere el inciso inicial del artículo 149.3 y que, por ello, pueden llegar a corresponder en toda su extensión a las Comunidades Autónomas en virtud de sus respectivos Estatutos de Autonomía.

De ahí que la interpretación constitucional que hasta ahora ha prevalecido, perfectamente establecida por el Tribunal Constitucional, consista:

- partiendo de la condición de Administración atribuida constitucionalmente a la instancia local, en

- entender que el régimen local (como materia) forma parte de la más genérica enunciada (como decimoctava entre las reservadas por el artículo 149.1 CE al Estado stricto sensu) como «bases del régimen jurídico de las Administraciones públicas y del régimen estatutario de sus funcionarios que, en todo caso, garantizarán a los administrados un tratamiento común ante ellas» ${ }^{2}$,

- con la consecuencia de la posibilidad de la asunción por las Comunidades Autónomas en sus Estatutos de Autonomía, en calidad de competencia para la legislación de desarrollo de las bases estatales, de la parte de la materia no comprendida por éstas.

\footnotetext{
2 Así lo dejó perfectamente establecido la STC 214/1989, de 21 de diciembre, al resolver sobre la constitucionalidad de la vigente Ley $7 / 1985$, de 2 de abril, reguladora de las bases del régimen local, al argumentar textualmente como sigue:

«En efecto, debe recordarse que en la STC 32/1981, de 28 de julio, ya se dijo que el núm. 18 del art. 149.1. ${ }^{\circ}$ de la Constitución, a diferencia de los demás apartados del mismo artículo, hace referencia «a una acción por así decir reflexiva del Estado (en el sentido más amplio del término), esto es, a la que el mismo lleva a cabo en relación al aparato administrativo que constituye su instrumento normal de actuación», añadiendo que «esta peculiaridad es importante, ya que entronca con el tema de la garantía institucional», de lo cual deduciría que corresponde al Estado la competencia para establecer las bases no sólo en relación a los aspectos organizativos o institucionales, sino también en relación a las competencias de los Entes locales constitucionalmente necesarios.
}

(...)

Pues bien, esta doctrina - reiterada en posteriores sentencias: fundamentalmente SSTC 76/1983, de 5 de agosto (F. J. $19 .^{\circ}$ ) y 27/1987, de 27 de febrero (F. J. $2 .^{\circ}$ ) - , según la cual debe ser el legislador estatal, con carácter general y para todo tipo de materias, el que fije unos principios o bases relativos a los aspectos institucionales (organizativos y funcionales) y a las competencias locales, encontrando cobertura a esa encomienda estatal en el concepto mismo de «bases del régimen jurídico de las Administraciones Públicas», por cuanto dicha expresión engloba a las Administraciones Locales - SSTC 25/1983, F. J. 4. ; 76/1983, F. J. 38. ${ }^{\circ}$; 99/1987, F. J. 2. ํ b) - , la que, con carácter general, inspira el sistema que articula la L. R. B. R. L. El «régimen local», que es, por tanto, el «régimen jurídico de las Administraciones Locales», resulta de este modo no una materia evanescente, disgregada en una pluralidad de asuntos sometidos a un régimen competencial diversificado tal como afirma la Generalidad de Cataluña, sino una materia con perfiles propios que, por imperativo de la garantía institucional de la autonomía local, contempla también - y no excluye- lo relativo a las competencias de los Entes locales». 
Sobre esta determinación de la distribución territorial de la competencia legislativa (el poder de organización de la instancia-ordenamiento local) en la materia descansa el régimen local actual, integrado por la Ley 7/1985, de 2 de abril, reguladora de las bases de aquél (pieza general), y, en cada Comunidad Autónoma (en su caso), la legislación de desarrollo de la misma (pieza particular autonómica); régimen local cuya constitucionalidad ha sido confirmada, en lo sustancial, por el Tribunal Constitucional (a partir de la STC 214/1989, de 21 de diciembre).

\subsection{El cuestionamiento de la situación establecida}

La dinámica propia del «proceso autonómico» (prolongado más allá de las previsiones de la norma fundamental, cuyo horizonte era el de «acceso» a la autonomía), la propia evolución del régimen local (significativamente el «exceso» regulatorio que ha supuesto su innovación en 2003 para las grandes poblaciones) y la frustración en la última legislatura de la iniciativa para la reforma de la Constitución (uno de cuyos objetivos era justamente la «estabilización» de la organización territorial certificando la conclusión del llamado «proceso autonómico») abriendo paso a la apertura de una cadena de reformas estatutarias (liderada - una vez en vía muerta la iniciativa del País Vasco - por Cataluña), ha puesto en cuestión la apuntada economía del régimen local.

Ese cuestionamiento se apoya en dos pilares:

1. La crítica del elemento más débil, en la interpretación constitucional, de dicha economía: la remisión a la legislación ordinaria y, en sede de ésta, a las «bases» a establecer por el Estado en sentido estricto (remisión de la que deriva la erección de dichas bases en límite negativo de la extensión de la competencia del legislador autonómico). De manera que lo que, en el momento constituyente, supuso una solución, hoy ha pasado a ser cuestión conflictiva (vista, desde el planteamiento autonómico, en especial el de las Comunidades con reivindicaciones nacionalistas). Pues:

- La práctica legislativa «básica» estatal es vista como abusiva de la noción de «bases», en expresión doctrinalmente acuñada: como conversora de lo que debieran ser bases de normación (naturalmente autonómica) en normación de bases.

- La doctrina sentada por el Tribunal Constitucional con ocasión del examen de la regularidad constitucional de la legislación básica es calificada como «condescendiente» con $-\mathrm{y}$, por tanto, legitimadora de - los que se califican como excesos del legislador estatal.

Nótese que esta crítica, en la medida en que persigue si no eliminar completamente, si limitar drásticamente el papel organizativo del Estado stricto sensu 
en la materia, encierra en último término un cuestionamiento del sistema constitucional de reparto territorial de competencias.

Pues éste descansa en gran medida en el recurso a la legislación estatal de bases para el cierre último (en sede de desarrollo constitucional) del deslinde competencial en buen número de materias y, desde luego, en la de régimen local. Se centra así en la degradación del objeto de lo reservado al Estado sobre la base de la doble afirmación de: i) la indeterminación constitucional de la noción de «bases»; y, consecuentemente, ii) la «desconstitucionalización» también en este aspecto del título VIII CE. Y de ello sigue que, por tanto, nada obsta a que los Estatutos de Autonomía «determinen» la extensión y el alcance de la competencia autonómica, entre otras, en materia de régimen local. Este es el soporte último, en efecto, de los argumentos aducidos por el dictamen número 269, de 1 de septiembre de 2005, del Consejo Consultivo de la Generalitat de Catalunya para legitimar el proyecto de reforma del Estatuto de Autonomía de Cataluña, sintiéndose así suficientemente pertrechado para sostener que, no existiendo una reserva general de Constitución que obligue a definir material y funcionalmente las competencias (por lo que, de hecho, el legislador estatal ha sido el que ha realizado dicha definición hasta ahora), la operación misma de concreción material y funcional de las mismas encuentra el único límite de la Constitución ${ }^{3}$.

Tal argumentación es circular y, por ello, más que discutible, pues la entrega de las bases al Estado en sentido estricto es una clara determinación constitucional que, en cuanto reserva a aquél justamente la definición de las bases, impone un límite asimismo claro a la asunción estatutaria de competencias. Por tanto, en modo alguno puede hablarse aquí de desconstitucionalización y sí sólo de abstracción de la delimitación constitucional del campo de competencia reservado al Estado en sentido estricto. Pero si esta abstracción, que no es - de otro ladoalgo peculiar de la noción constitucional de bases y es nota común de muchas prescripciones constitucionales, conduce a un amplio margen de configuración en sede de la legislación ordinaria (para lo que no es necesario recurrir a la tesis de la desconstitucionalización), no se vislumbra en modo alguno la razón por la que sea legítimo constitucionalmente su ejercicio en sede de los Estatutos de Autonomía (que son ciertamente normas legales orgánicas muy peculiares, pero normas legales ordinarias al fin y a la postre, en el sentido de fruto del ejercicio del poder legislativo constituido) y no así, por el contrario, en la de la legislación básica estatal. Y ello, teniendo en cuenta que la residencia de la concreción com-

\footnotetext{
3 En relación con esta interpretación véase en la doctrina F. VELASCO CABALLERO, «Comentario a la ponencia de Tomás FONT Y LLOVET «El régimen local en la reforma de los Estatutos de Autonomía», en El régimen local en la reforma de los Estatutos de Autonomía, CEPC, Madrid, 2006, págs. 41 y sgs.; así como anteriormente «Organización territorial y régimen local en la reforma del Estatuto de Cataluña: límites constitucionales, en Estudios sobre la reforma del Estatuto, IEA, Barcelona, 2004, págs. 283 y sgs.; y también «Autonomía local y subsidiariedad en la reforma de los Estatutos de Autonomía», Anuario de Gobierno Local 2004, págs. 217 y ss.; Marc CARRILLO, La Administración local en la reforma de los Estatutos de Autonomía: especial referencia al caso del Estatuto de Autonomía de Cataluña, Cuadernos de Derecho Local, núm. 12 (2006), págs. 38 y sgs.
} 
petencial en los Estatutos implica cuando menos la delimitación negativa (potencialmente diversa) de lo que sean las bases, es decir, del campo competencial estatal y, por tanto, de la consistencia y alcance del desarrollo constitucional general del principio y la garantía de la autonomía local.

Tanto más cuanto que: i) es (desde el punto de vista del orden constitucional) la legislación básica estatal la lógicamente llamada a desarrollar primariamente la garantía institucional de la autonomía, que es general por alusiva a un modelo de Estado (global), y a concretar el alcance de dicha autonomía en cuanto principio del sistema de distribución territorial de competencias (por ser ésta necesariamente una cuestión situada, en lo que atañe a la garantía, fuera del círculo de intereses propio de la autonomía reconocida a las Comunidades Autónomas, a todas ellas); y ii) la legislación estatal está por ello, recuérdese, expresamente aludida, como presupuesta, en el artículo $148.1,2 .{ }^{\text {a }} \mathrm{CE}$.

De lo que resulta que el fundamento último de la argumentación no es sino la deliberada reinterpretación del marco constitucional al servicio de un modelo territorial alternativo al resultante del desarrollo constitucional acaecido sobre la base de la insatisfacción misma con el resultado de tal desarrollo. Pretensión ésta que lo que plantea es la cuestión de si es también constitucional (en los mismos términos que el desarrollo real) o si, por el contrario, supone cuando menos una verdadera mutación constitucional.

2. ${ }^{\circ}$ La conveniencia de la «interiorización» de la instancia local por las Comunidades Autónomas (objetivo confesado de las reformas estatutarias, singularmente de la del estatuto de Autonomía de Cataluña), en la medida en que puede aparecer, en función también de la argumentación anterior, i) políticamente, como «avance en la descentralización», por más que sea en realidad ambivalente y pueda verse también como incremento de una paradójica mayor centralización policéntrica (por autonómica), y ii) jurídicamente, como solución positiva para la garantía constitucional de la autonomía local en la medida en que supera las insuficiencias protectoras de su entrega a la legislación ordinaria sin mayor cualificación. Y ello gracias a la peculiaridad de los Estatutos de Autonomía: Ley orgánica dotada de una específica rigidez. Lo que se silencia es que lo que se consigue en todo caso es una mayor rigidez de las concreciones del modelo territorial autonómico (entendido como comprensivo de la instancia local) justamente frente al modelo general de Estado, cuya concreción primaria general está encomendada (por lo que hace a la instancia local) al Estado en sentido estricto, debilitando, en consecuencia, el alcance y la efectividad de la concreción de dicho modelo general.

La base para la viabilidad de esta «interiorización» la proporciona, de nuevo, la desconstitucionalización del régimen local. Desde ella se afirma que, dada la «bifrontalidad» del régimen local, los límites de la competencia autonómica en la materia no vienen dados por la legislación estatal básica existente en cada momento. Pues ésta, aunque sea constitucional (como ocurre con la Ley básica 
vigente), lo es no por ser la única constitucionalmente posible, sino por no ser inconstitucional. No siendo lo básico establecido legislativamente una decisión directa de la Constitución y cupiendo así en ésta diversos modelos de organización territorial del Estado, se concluye que lo básico actual es sólo la consecuencia directa de una generalizada «autorrestricción» de los Estatutos de Autonomía a la hora de la definición de la competencia autonómica en materia de régimen local. El resultado es que lo único decisivo son los límites constitucionales a la asunción de competencias en los Estatutos de Autonomía, pues dichos límites no pueden, por lo dicho, derivar sin más de la legislación básica.

Aunque también esta argumentación sea, en si misma, cuestionable (en particular la tesis de la supuesta «autorrestricción» de los Estatutos de Autonomía antes de las reformas aún en curso), cabe convenir — en aras de la brevedad en que los límites últimos a la autonomía están directamente en la Constitución; conclusión ésta, que en modo alguno es novedosa, porque la cuestión no está en ella, sino en si tales límites se extienden a lo básico que los concrete (en la función de desarrollo constitucional). Como esto último no parece que pueda ser cuestionado por las razones ya expuestas, aquella conclusión debe ser complementada con tal prolongación - en el escalón legislativo ordinario básico - de los límites constitucionales (en términos de límites derivados del bloque de la constitucionalidad, pues conforme al artículo 28.1 de la Ley orgánica del Tribunal Constitucional, las Leyes dictadas — dentro del marco constitucional — para delimitar las competencias del Estado y de las diferentes Comunidades Autónomas forman parte de dicho bloque justamente a tales efectos competenciales). Con la consecuencia de que la distribución territorial de competencias en la materia sigue consistiendo en la reserva al Estado en sentido estricto de la definición de lo básico y entrega a las Comunidades del resto de la materia. Lo que significa que el límite actual de la competencia legislativa autonómica persiste y lo único que cambia es la determinación del contenido y alcance de lo básico. Aspecto este último, en el que la cuestión es muy distinta: la de — dada la lógica propia del bloque «bases-desarrollo» - quién está llamado a definir lo básico en primera instancia y con prevalencia a cualquier otra en el curso del desarrollo constitucional, sin perjuicio de que tal definición esté sujeta siempre a la última palabra del Tribunal Constitucional.

No obstante, debe tenerse en cuenta la ambigüedad que en este punto ha introducido la STC 247/2007, de 12 de diciembre, al sostener que los Estatutos de Autonomía pueden delimitar el alcance de las funciones propias de las competencias estatales, si bien con el límite de su no desnaturalización, haciéndolas irrecognoscibles en cuanto instituciones.

\subsection{La situación resultante de las reformas estatutarias}

Aunque no todas las reformas estatutarias se encuentran concluidas, las ya culminadas pueden tenerse por suficientemente representativas de las conse- 
cuencias que, en conjunto, han de derivarse $-\mathrm{y}$, en gran medida se han derivado ya- del antes analizado cuestionamiento del modelo que encuentra su formalización general última en la vigente Ley 71985, de 2 de abril, reguladora de las bases del régimen local.

\subsubsection{Los nuevos Estatutos de Autonomía con menor pretensión de «interiorización»}

\subsubsection{Análisis}

Un primer grupo de nuevos Estatutos de Autonomía - los de las Islas Baleares y Castilla y León, aprobados por Leyes orgánicas 1/2007, de 28 de febrero, y 12/2007, de 30 de noviembre, respectivamente, al que puede agregarse aún el de Aragón, aprobado por Ley orgánica 5/2007, de 20 de abril - no supone innovación relevante en la situación establecida, toda vez que:

- El de las Islas Baleares sólo incluye entre las instituciones propias de la Comunidad Autónoma (art. 39) los Consejos Insulares, que no pertenecen — ni en la Constitución, ni en la legislación básica - a las entidades locales necesarias en todo el territorio nacional, asumiendo como competencia exclusiva (art. 38) únicamente la materia enunciada como «alteración de los términos municipales y denominación oficial de los Municipios y topónimos», de suerte que la materia «régimen local» aparece en el apdo. 13 del artículo 31 entre las competencias que se asumen en términos funcionales de desarrollo legislativo y ejecución en el marco de la legislación básica del Estado. Y dedica ciertamente uno de los capítulos (el V; integrado por un solo artículo, el 75) de su título IV relativo a las instituciones de la Comunidad Autónoma a «los Municipios y demás entidades locales», pero ello exclusivamente para establecer prescripciones sin trascendencia significativa para la cuestión que aquí importa ${ }^{4}$.

\footnotetext{
4 Son las siguientes: i) el Municipio es la entidad local básica de la organización territorial de las Illes Balears y el instrumento fundamental para la participación de la comunidad local en los asuntos públicos, correspondiendo su gobierno y administración al Ayuntamiento formado por el alcalde o la alcaldesa, los concejales (elegidos éstos por los vecinos mediante sufragio universal, igual, libre, directo y secreto) y los demás miembros que, en su caso establezcan las Leyes; ii) la garantía estatutaria a los municipios de autonomía para el ejercicio de sus competencias propias, bajo su responsabilidad y en defensa de los intereses de la colectividad que representan; la sujeción en dicho ejercicio sólo al control de constitucionalidad y legalidad; y de su libertad plena, en el ámbito del Estatuto y de las Leyes, para el ejercicio de su iniciativa en cualquier materia que no esté excluida de su competencia o atribuida en exclusiva a otra administración o autoridad; iii) el reconocimiento a los Municipios, además de las competencias derivadas de la legislación básica del Estado y de la legislación sectorial, de las que puedan ser delegadas por el Estado, por la Comunidad Autónoma, por los Consejos Insulares y por otras Administraciones (con acompañamiento de los medios económicos, personales y materiales adecuados y suficientes), así como la posibilidad de asumir en su ámbito territorial la función ejecutiva y la gestión de las competencias propias de los Consejos Insulares o de las que previamente les sean transferidas y, por último, su derecho a asociarse con otros y a cooperar entre ellos y con otros entes públicos para ejercer sus competencias y para cumplir tareas de interés común (constituyendo, en particular, mancomunidades, consorcios y asociaciones); iv) la aprobación por el Parla-
} 
- El de Castilla y León diferencia perfectamente entre las instituciones de autogobierno de la Comunidad Autónoma (a las que dedica el título II) y la organización territorial de la misma (título III), comprendiendo la regulación de ésta solo, además de las relaciones entre la Comunidad Autónoma y dichos entes locales, prescripciones de porte equivalente a las del Estatuto de las Islas Baleares ${ }^{5}$. En punto a competencias, si bien incluye la organización territorial de la Comunidad (inclusiva de las relaciones entre las instituciones autonómicas y los entes locales y la regulación de los entes locales creados por la Comunidad) entre las materias objeto de las exclusivas (art. 70.1), precisa inmediatamente (en el apdo. 3 del propio art. 70) que la atribución en exclusividad de las correspondientes competencias se entenderá efectuada sin perjuicio de las competencias que pudieran corresponder al Estado en virtud de otros títulos previstos por la Constitución. Por lo que es plenamente congruente que inserte (art. 71.1.1. ${ }^{\circ}$ ) la materia «régimen local» entre las competencias de desarrollo normativo y ejecución a ejercer en el marco de la legislación básica del Estado y, en su caso, en los términos que ella establezca.

mento, en el marco de la legislación básica del Estado, de una Ley de régimen local teniendo en cuenta necesariamente las diferentes características demográficas, geográficas, organizativas, de dimensión y capacidad de gestión, así como las competencias de cooperación local asumidas por los Consejos Insulares; v) la disposición por los Municipios de recursos suficientes para ejercer las funciones que les atribuye la legislación y que deben ser garantizados por la Administración del Estado, la autonómica y la insular; y vi) e dictado para el Municipio de Palma de una Ley de capitalidad especial, reconociendo al Ayuntamiento de Palma iniciativa para proponer la modificación de su régimen especial y su participación, de acuerdo con las Leyes y el Reglamento del Parlamento, en la elaboración de los proyectos de Ley que incidan en tal régimen especial.

5 Son las contenidas en los artículos 44 a 47, que se refieren a: i) la definición del Municipio como entidad territorial básica de la Comunidad y la institución de participación más directa de los ciudadanos en los asuntos públicos, dotada de personalidad jurídica propia y plena autonomía en el ámbito de sus competencias y en la defensa de los intereses locales que representa, correspondiendo su gobierno, representación y administración al Ayuntamiento y verificándose su creación y supresión y fusión, así como la alteración de sus términos de acuerdo con la legislación de la Comunidad Autónoma en el marco de la legislación básica del Estado; ii) el reconocimiento a los Municipios - para su ejercicio con plena autonomía - de las competencias propias establecidas por la legislación básica del Estado y la de la Comunidad Autónoma, desde la regla general de que las competencias de las entidades locales les corresponden, salvo que la Ley las asigne a otras entidades locales, así como la atribución de la capacidad para ejercer su iniciativa en toda materia de interés local que no esté expresamente excluida de su competencia o atribuida a otras Administraciones por la legislación del Estado o de la Comunidad Autónoma; iii) la configuración de la comarca como la agrupación voluntaria de Municipios limítrofes con características geográficas, económicas, sociales e históricas afines, que puede ser también circunscripción administrativa de la Junta de Castilla y León para el cumplimiento de sus fines y cuya constitución debe formalizarse por Ley de las Cortes (con independencia de su regulación legal general y de la singular de la comarca del Bierzo) definitoria de sus competencias, sin perjuicio de las que puedan delegarle o encomendarle (con el acuerdo de los Ayuntamientos afectados) las entidades locales de su ámbito territorial o la Comunidad Autónoma; y iv) la dotación de la Provincia-entidad local (sin perjuicio de su paralela condición de división territorial para el cumplimiento de los fines de la Comunidad Autónoma) con personalidad jurídica propia y capacidad plena para la gestión de sus intereses, correspondiendo su gobierno y administración a la Diputación y asignándose sus competencias por la legislación básica del Estado y la de la Comunidad Autónoma, pero debiendo ejercer en todo caso competencias en el ámbito de la cooperación, asesoramiento y asistencia a Municipios y otras entidades locales, así como prestar servicios supramunicipales de carácter provincial en el ámbito de las competencias locales (todo ello, sin perjuicio de las que puedan delegarle o encomendarle las entidades locales de su ámbito territorial o la Comunidad Autónoma). 
- También el Estatuto de Autonomía de Aragón, que va algo más lejos que los dos anteriores, incorpora tanto una regulación (título II) de la organización institucional de la Comunidad Autónoma - incluyendo en ella sólo a las Cortes de Aragón, el Presidente de Aragón, el Gobierno o Diputación General de Aragón y el Justicia de Aragón - y otra (título VI) de la organización territorial y gobierno local, estructurando ésta en municipios, comarcas y provincias (con habilitación para la creación, por Ley de áreas metropolitanas y la regulación de entidades de ámbito territorial inferior al municipio) y estableciendo determinaciones sobre el Municipio ${ }^{6}$, la Comarca $^{7}$, la Provincia $^{8}$ y las relaciones entre la Comunidad Autónoma y los entes locales ${ }^{9}$, incluyendo la creación de un Consejo Local de Aragón y la previsión de un régimen especial para Zaragoza en cuanto capital (arts. 85 a 87).

Cuando aborda las competencias de la Comunidad Autónoma y tras diferenciar entre competencias exclusivas, compartidas y ejecutivas, disponiendo con carácter general su ejercicio respetando lo dispuesto en la Constitución y en el Estatuto, asume las siguientes:

a) La competencia exclusiva (comprensiva de la potestad legislativa, la potestad reglamentaria y la función ejecutiva respetando lo dispuesto en los artículos 140 y $149.1 \mathrm{CE}$ ) entre otras y «en materia de régimen local»: la determinación de las competencias de los municipios y demás entes locales en las materias de competencias de la Comunidad Autónoma de Aragón; el régimen de los bienes locales y las modalidades de prestación de los servicios públicos locales, así como las relaciones para la cooperación y colaboración entre los entes locales y entre éstos y la Administración de la Comunidad Autónoma de Aragón; y también la determinación de los órganos de gobierno de los entes locales creados por la Comunidad Autónoma y su régimen electoral (art. 74).

\footnotetext{
6 Conforme al artículo 82, los Municipios son las entidades territoriales básicas de Aragón, dotadas de personalidad jurídica y autonomía para la gestión de sus intereses respectivos, y medio esencial de participación de la comunidad vecinal en los asuntos públicos, cuyo gobierno y la administración municipales corresponde al Ayuntamiento, formado por el Alcalde y los concejales; todo ello desde la garantía de su autonomía en el ejercicio de las competencias propias y la defensa de los intereses de la colectividad que representan y con habilitación a la Ley autonómica para establecer los requisitos para la aplicación del régimen de Concejo abierto).

7 A tenor del artículo 83, las Comarcas son entidades territoriales, constituidas por la agrupación de Municipios limítrofes, vinculados por características e intereses comunes, fundamentales para la vertebración territorial aragonesa, que tienen a su cargo la prestación de funciones y servicios y la gestión de actividades de ámbito supramunicipal, representando los intereses de la población y territorio comarcales en defensa de una mayor solidaridad y equilibrio territorial. Su creación, modificación y supresión, así como la determinación de sus competencias, organización y régimen jurídico se producen por Ley autonómica.

8 Según el artículo 84, las Provincias son entidades locales supramunicipales con personalidad jurídica propia y ejercen funciones de cooperación, asistencia y prestación de servicios a Municipios y Comarcas, atendiendo en todo caso a criterios de solidaridad y equilibrio territorial.

9 En este contexto determina muy significativamente que la Ley autonómica distribuye las responsabilidades administrativas entre los distintos niveles de organización territorial de acuerdo con la legislación básica estatal.
} 
b) La competencia compartida consistente en el desarrollo legislativo y la ejecución de la legislación básica que establezca el Estado en normas con rango de Ley, entre otras, en la materia «El desarrollo de las bases del Estado previstas en el artículo 149.1.18 de la Constitución para las Administraciones Públicas aragonesas, incluidas las Entidades Locales» (art. 75).

Siendo los términos de esta asunción competencial altamente significativos de la interpretación, en este punto, del sistema de distribución territorial de competencias.

\subsubsection{Conclusiones}

El simple resumen del contenido dispositivo pertinente del grupo de Estatutos de Autonomía examinado confirma plenamente el juicio avanzado de que dicho contenido no representa cambio apreciable en la situación establecida en cuanto al reparto territorial de la competencia entre el Estado stricto sensu y las Comunidades Autónomas en materia de régimen local. Pues:

1. $\quad$ La directa regulación de la organización territorial interna de la Comunidad Autónoma no pone en cuestión la posición constitucional propia de $\mathrm{Mu}$ nicipios y Provincias en la organización del Estado en su conjunto y es equivalente en su alcance (salvo la legítima plena conversión en instituciones autonómicas de los Consejos Insulares en el Estatuto de las Islas Baleares) a la que desde siempre han establecido los Estatutos de Autonomía.

2. $\quad$ La asunción de competencias en materia de régimen local, ni fragmenta ésta mediante diferenciación de la organización territorial autonómica, ni altera la brifontalidad de los entes locales (a efectos competenciales), ni pone en cuestión la ubicación constitucional de aquella materia (para la distribución territorial de competencias) en la más amplia del artículo 149.1.18 CE relativa al régimen jurídico de las Administraciones públicas. Lo primero porque, i) aún contemplando competencias autonómicas exclusivas, circunscribe éstas bien al ámbito del título contemplado en el artículo 148.1.2 CE, bien a éste ampliado a la regulación de los entes de creación autonómica (ya tenido en cuenta por la legislación básica de régimen local vigente); y ii) configura en el resto la competencia autonómica como de desarrollo legislativo y ejecución de las bases estatales, en concreto en cuanto admite expresamente la reserva al Estado de la legislación básica y el juego de la autonómica sólo en el desarrollo legislativo y la ejecución, así como tampoco la ubicación de la materia. Y lo segundo, porque esta última competencia autonómica se refiere a la legislación básica que se presupone, así, dictada al amparo del citado artículo 149.1.18 CE. 


\subsubsection{Los nuevos Estatutos con mayor pretensión de «interiorización»}

\subsubsection{Análisis}

El resto de las reformas estatutarias ya aprobadas y en vigor pretenden tener un mayor alcance en la «interiorización» de la Administración local y, por tanto, en la asunción de competencia en la materia «régimen local», en este caso mediante la fijación de un límite «por abajo» a la del Estado stricto sensu. Se trata de los nuevos Estatutos de Autonomía de Valencia (aprobado por Ley orgánica 1/2006, de 10 de abril), Andalucía (aprobado por Ley orgánica 2/2007, de 19 de marzo) y Cataluña (aprobado por Ley orgánica 6/2006, de 19 de julio). Veámoslos por separado:

- En el caso de la Comunidad Autónoma de Valencia, la regulación de las instituciones autonómicas y de la Administración Local aparecen separadas. La primera integra el título III (art. 20), determinando la Generalidad como el conjunto de instituciones de autogobierno integrado por las Cortes Valencianas, el Presidente y el Consejo, a los que se añaden en calidad de instituciones autonómicas la Sindicatura de Cuentas, el Síndico de Greuges, el Consejo Valenciano de Cultura, la Academia Valenciana de la Lengua, el Consejo Jurídico Consultivo y el Comité Económico y social. La segunda se agrupa en el título II bajo la rúbrica «Administración Local», comprendiendo disposiciones generales ${ }^{10} \mathrm{y}$ preceptos referidos concretamente a los Municipios ${ }^{11}$,

10 Conforme al artículo 63: a) las entidades locales administran con autonomía los asuntos propios, de acuerdo con la Constitución y el Estatuto; b) las Administraciones públicas locales de la Comunidad se rigen en sus relaciones por los principios de coordinación, cooperación y colaboración; c) la Generalidad y los entes locales pueden crear órganos de cooperación, con composición bilateral o multilateral, de ámbito general o sectorial, en aquellas materias en las que existan competencias compartidas, con fines de coordinación y cooperación según los casos; y c) la legislación autonómica debe fomentar la creación de figuras asociativas entre las Administraciones públicas para mejorar la gestión de los intereses comunes y para garantizar la eficacia en la prestación de servicios.

11 Según el artículo 64: i) los Municipios están regidos por Ayuntamientos de carácter representativo, elegidos por sufragio universal, igual, libre, directo y secreto, como establezca la Ley, aprobando las Cortes valencianas, en el marco de la legislación básica del Estado, la Ley de Régimen Local de la Comunidad; ii) las Cortes Valencianas impulsan la autonomía local, pudiendo delegar la ejecución de las funciones y competencias en aquellos Ayuntamientos y entes locales supramunicipales que, por sus medios, puedan asumirlas, asegurando la debida coordinación y eficacia en la prestación de los servicios, pero debiendo la distribución de las responsabilidades administrativas entre las diversas administraciones locales tener en cuenta su capacidad de gestión y rigiéndose por el principio de subsidiariedad, de acuerdo con lo que establece la Carta europea de la autonomía local y por el principio de diferenciación, de acuerdo con las características que presenta la realidad municipal (con procedencia de la descentralización, mediante Ley y en favor de los Ayuntamientos, de aquellas competencias que sean susceptibles de ello, atendiendo a la capacidad de gestión de los mismos; descentralización que debe ir acompañada de los suficientes recursos económicos para que sea efectiva), iii) la creación por Ley del Fondo de Cooperación Municipal de la Comunidad (con los mismos criterios que el fondo estatal) para potenciar la autonomía local sobre la base del principio de subsidiariedad; y iv) la creación de una Comisión Mixta entre la Generalidad y la Federación Valenciana de Municipios y Provincias como órgano deliberante y consultivo para determinar las bases y métodos que favorezcan las 
las Comarcas ${ }^{12}$ y las Diputaciones provinciales ${ }^{13}$. Y en punto a las competencias, la fórmula de la asunción es simple, pues contempla el «régimen local» como una materia única comprensiva de todos los aspectos atinentes al estatuto de la Administración. En efecto, conforme al artículo 49.1.8. ${ }^{\mathrm{a}}$ la Comunidad tiene competencia exclusiva en la materia «régimen local, sin perjuicio de lo que dispone el número 18 del apartado 1 del artículo 149 de la Constitución española. Alteraciones de los términos municipales y topónimos».

- El Estatuto de Andalucía dedica asimismo un título (el III) a la organización territorial de la Comunidad Autónoma, pero diferenciando perfectamente el contenido de éste de la regulación de la organización institucional propia de dicha Comunidad (a la que dedica el título IV, referido a la Junta de Andalucía y distinguiendo el Parlamento -incluyendo la elaboración de las normas - , el Presidente de la Junta, el Consejo de Gobierno - incluyendo sus relaciones con el Parlamento-, otras instituciones de autogobierno - Defensor del Pueblo Andaluz, Consejo Consultivo, Cámara de Cuentas, Consejo Audiovisual de Andalucía y Consejo Económico y Social - y Administración de la Junta de Andalucía.

La regulación de la organización territorial de la Comunidad Autónoma comienza (arts. 89 y 90) con tres determinaciones generales: la estructuración territorial en Municipios, Provincias y demás entidades territoriales que puedan crearse por Ley; el ajuste de las relaciones entre la Administración de la Comu-

\footnotetext{
bases de participación entre dichas instituciones, con función de informe preceptivo de las iniciativas legislativas que afecten de manera específica a las entidades locales y de planes y normas reglamentarias de idéntico carácter.

12 1. El artículo 65: a) habilita a la Ley autonómica (aprobada con quorum reforzado previa consulta a las entidades locales) para, en el marco de la legislación del Estado, determinar la división comarcal; b) define las Comarcas como circunscripciones administrativas de la Generalidad y entidades locales determinadas por la agrupación de Municipios para la prestación de servicios y gestión de asuntos comunes; y c) contempla la regulación por Ley autonómica (adoptada con quórum reforzado y previa consulta de las entidades locales) de las áreas metropolitanas y las agrupaciones de Comarcas.

13 A tenor del artículo 66: 1) las Diputaciones provinciales son expresión de la autonomía provincial, de acuerdo con la Constitución, la legislación del Estado y el Estatuto, desempeñando las funciones consignadas en la legislación del Estado y las delegadas por la Comunidad; 2) el legislador autonómico está habilitado para transferir o delegar en las Diputaciones provinciales la ejecución de aquellas competencias que no sean de interés general de la Comunidad; 3) la coordinación por la Generalidad de las funciones propias de las Diputaciones provinciales que sean de interés general de la Comunidad, estableciendo la Ley autonómica (adoptada con quórum reforzado), en el marco de la legislación del Estado, las fórmulas generales de coordinación y la relación de las funciones que deben ser coordinadas, fijando, en su caso, las singularidades que, según la naturaleza de la función, sean indispensables para su más adecuada coordinación; y 4) la actuación de las Diputaciones provinciales como instituciones de la Generalidad, quedando sometidas a la legislación, reglamentación e inspección de ésta, en tanto que se ejecutan competencias delegadas por la misma (pudiendo el Consejo, en caso de incumplimiento de las obligaciones legales y previo requerimiento al Presidente de la Diputación de que se trate, adoptar las medidas necesarias para obligar al cumplimiento forzoso y siendo revocable (mediante Ley adoptada con quórum reforzado) la delegación de la ejecución de aquellas competencias en las que la actuación de las Diputaciones atente al interés general de la Comunidad.
} 
nidad Autónoma y las Administraciones locales a los principios de información mutua, coordinación, colaboración y respeto a los ámbitos competenciales correspondientes determinados en el Estatuto, la legislación básica del Estado y la normativa autonómica de desarrollo, con plena observancia de la garantía institucional de la autonomía local reconocida por la Constitución y por la Carta Europea de la Autonomía Local; y el establecimiento de la autonomía, responsabilidad, cooperación, desconcentración, descentralización, subsidiariedad, coordinación, suficiencia financiera y lealtad institucional como principios de la referida estructura. Y siguen a estas determinaciones regulaciones referidas a: i) el escalón municipal: Municipio ${ }^{14}$; agrupaciones municipales (áreas metropolitanas, mancomunidades, consorcios y otras, cuyas funciones se regulan por Ley; art. 94); y órgano mixto - con representación de la Junta de Andalucía y de los Ayuntamientos - como ámbito permanente de diálogo y colaboración institucional (art. 95); ii) la Provincia ${ }^{15}$; y iii) y la Comarca ${ }^{16}$.

\section{Dos aspectos de esta organización territorial merecen ser destacados:}

1. ${ }^{\circ}$ Incluye la previsión (art. 98) del dictado - en el marco de la legislación básica del Estado - de una Ley (autonómica) de régimen local que regule las relaciones entre las instituciones de la Junta de Andalucía y los entes locales, así como las técnicas de organización y de relación para la cooperación y la colaboración entre los entes locales y entre éstos y la Administración de la Comunidad Autónoma, incluyendo las distintas formas asociativas mancomunales, convencionales y consorciales, así como cuantas materias se deduzcan del artículo 60 (relativo a la competencia autonómica en la materia).

14 El artículo 91 establece: i) el Municipio es la entidad territorial básica de la Comunidad Autónoma, que goza de personalidad jurídica propia y de plena autonomía en el ámbito de sus intereses, correspondiendo su representación, gobierno y administración corresponden a los respectivos Ayuntamientos; ii) la alteración de términos municipales y la fusión de Municipios limítrofes de la misma Provincia se realizan de acuerdo con la legislación autonómica dictada en el marco de la legislación básica del Estado; y iii) los Municipios disponen de plena capacidad de autoorganización dentro del marco de las disposiciones generales establecidas por Ley en materia de organización y funcionamiento municipal.

15 Conforme al artículo 96: i) la Provincia es una entidad local con personalidad jurídica propia, determinada por la agrupación de municipios, debiendo cualquier alteración de sus límites ser aprobada por las Cortes Generales mediante Ley orgánica y correspondiendo su gobierno y administración (con autonomía) a la Diputación como órgano representativo de la misma; ii) son competencias de la Diputación: a) la gestión de las funciones propias de la coordinación municipal, asesoramiento, asistencia y cooperación con los Municipios, especialmente los de menor población que requieran de estos servicios, así como la posible prestación de algunos servicios supramunicipales, en los términos y supuestos que establezca la legislación de la Comunidad Autónoma; b) las que con carácter específico y para el fomento y la administración de los intereses peculiares de la Provincia le vengan atribuidas por la legislación básica del Estado y por la legislación que dicte la Comunidad Autónoma en desarrollo de la misma; y c) las que pueda delegarle para su ejercicio la Comunidad Autónoma, siempre bajo la dirección y el control de ésta; iii) la Junta de Andalucía coordina en todo caso los planes provinciales de obras y servicios y la actuación de las Diputaciones en materias de interés general para Andalucía (interés, cuya apreciación y las fórmulas de coordinación se establecen por Ley aprobada por mayoría absoluta y en el marco de lo que disponga la legislación básica del Estado.

16 A tenor del artículo 97, la Comarca se configura como la agrupación voluntaria de Municipios limítrofes con características geográficas, económicas, sociales e históricas afines regulada por Ley autonómica en cuanto a su creación de y competencias. 
2. Además de previsiones sobre la transferencia y la delegación de competencias por parte de la Comunidad Autónoma (art. 93), su regulación del Municipio presenta la peculiaridad de establecer (art. 92): a) una garantía a los Municipios de un núcleo competencial propio actuado con plena autonomía y sujeción sólo a los controles de constitucionalidad y legalidad; y b) una asignación directa a los mismos - en los términos que especifiquen las Leyes - de competencias propias (en todo caso) en un elenco de materias ${ }^{17}$; regulación que, por tanto, presenta una estructura paralela al actual artículo 25.1 de la Ley estatal 7/1985, de 2 de abril, reguladora de las bases del régimen local.

Por lo que hace a las competencias de la Comunidad Autónoma, el Estatuto parte - al igual que el de Cataluña, que luego se analizará - de una clasificación formal de las competencias en exclusivas, compartidas y ejecutivas, definiendo cada una de estas clases en los siguientes términos (art. 42):

a) Las competencias exclusivas comprenden la potestad legislativa, la potestad reglamentaria y la función ejecutiva, íntegramente y sin perjuicio de las competencias atribuidas al Estado en la Constitución, siendo - en el ámbito acotado por ellas - el Derecho andaluz de aplicación preferente en su territorio sobre cualquier otro, teniendo el Derecho estatal carácter supletorio.

b) Las competencias compartidas comprenden la potestad legislativa, la potestad reglamentaria y la función ejecutiva en el marco de las bases que fije el Estado en normas con rango de Ley, excepto en los supuestos que se determinen de acuerdo con la Constitución.

c) Las competencias ejecutivas comprenden la función ejecutiva, que incluye la potestad de organización de su propia Administración y, en general, aquellas funciones y actividades que el ordenamiento atribuye a la Administración pública y, cuando proceda, la aprobación de disposiciones reglamentarias para la ejecución de la normativa del Estado.

En coherencia con la regulación de la estructura territorial de la Comunidad Autónoma, se atribuye a ésta (arts. 59 y 60) las siguientes competencias:

17 Se trata de las siguientes: a) ordenación, gestión, ejecución y disciplina urbanística; b) planificación, programación y gestión de viviendas y participación en la planificación de la vivienda de protección oficial; c) gestión de los servicios sociales comunitarios; d) ordenación y prestación de los siguientes servicios básicos: abastecimiento de agua y tratamiento de aguas residuales; alumbrado público; recogida y tratamiento de residuos; limpieza viaria; prevención y extinción de incendios y transporte público de viajeros; e) conservación de vías públicas urbanas y rurales; f) ordenación de la movilidad y accesibilidad de personas y vehículos en las vías urbanas; g) cooperación con otras Administraciones públicas para la promoción, defensa y protección del patrimonio histórico y artístico andaluz; h) cooperación con otras Administraciones públicas para la promoción, defensa y protección del medio ambiente y de la salud pública; i) regulación de las condiciones de seguridad en las actividades organizadas en espacios públicos y en los lugares de concurrencia pública; j) defensa de usuarios y consumidores; k) promoción del turismo; 1) promoción de la cultura, así como planificación y gestión de actividades culturales; $\mathrm{m}$ ) promoción del deporte y gestión de equipamientos deportivos de uso público; n) cementerio y servicios funerarios; y ñ) las restantes materias que con este carácter sean establecidas por las leyes. 
1. La competencia exclusiva en las dos siguientes materias:

1. Organización territorial (se entiende en el sentido que esta expresión, como ha quedado visto, tiene en el propio Estatuto), respetando la garantía institucional establecida por la Constitución en los artículos 140 y 141 e incluyendo en todo caso: i) la determinación, la creación, la modificación y la supresión de las entidades que configuran la organización territorial de Andalucía; y ii) la creación, la supresión y la alteración de los términos de los entes locales y las Comarcas que puedan constituirse, así como denominación y símbolos.

2. $\quad$ La parte del régimen local que, respetando el artículo 149.1.18 de la Constitución y el principio de autonomía local, incluye: i) las relaciones entre las instituciones de la Junta de Andalucía y los entes locales, así como las técnicas de organización y de relación para la cooperación y la colaboración entre los entes locales y entre éstos y la Administración de la Comunidad Autónoma, incluyendo las distintas formas asociativas mancomunales, convencionales y consorciales; ii) la determinación de las competencias y de las potestades propias de los Municipios y de los demás entes locales, en los ámbitos especificados en el Título III; iii) el régimen de los bienes de dominio público, comunales y patrimoniales y las modalidades de prestación de los servicios públicos; iv) la determinación de los órganos de gobierno de los entes locales creados por la Junta de Andalucía, el funcionamiento y el régimen de adopción de acuerdos de todos estos órganos y de las relaciones entre ellos; v) el régimen de los órganos complementarios de la organización de los entes locales; y vi) la regulación del régimen electoral de los entes locales creados por la Junta de Andalucía, con la excepción de los constitucionalmente garantizados.

2. La competencia compartida en la parte del régimen local no incluida en la competencia exclusiva anterior (lo que quiere decir en lo que aquí importa: la legislación en el marco de las bases establecidas por el Estado), así como en las haciendas locales y la tutela financiera sobre los entes locales (aquí, con la especificidad de que la competencia opera en el marco de la regulación general del Estado y dentro de las bases que dicte el Estado de acuerdo con el artículo 149.1.18 de la Constitución).

- Finalmente, el Estatuto de Autonomía de Cataluña descansa, en lo que ahora importa, sobre las siguientes determinaciones:

1. ${ }^{\text {a }}$ La definición (art. 2.1) de la Generalidad como el sistema institucional en que se organiza políticamente el autogobierno de Cataluña; sistema, que está integrado por el Parlamento, la Presidencia, el Gobierno y las demás instituciones que establece el Capítulo V, del Título II. 
2. ${ }^{\text {a }}$ La declaración separada (art. 2.2) de los Municipios, las Veguerías, las Comarcas y los demás entes locales que las Leyes determinen como también integrantes del sistema institucional de la Generalidad, pero - como inmediatamente se precisa - en calidad de entes en los que ésta se organiza territorialmente, sin perjuicio de su autonomía.

Bajo la imprecisa rúbrica «De las instituciones» (imprecisa por no especificar deliberadamente el carácter de tales instituciones, en congruencia con la economía interna del artículo 2), el título II incluye, en efecto, un capítulo (el IV) relativo al Gobierno local, que se estructura en las siguientes secciones:

a) La referida a la «organización territorial local», comprensiva de prescripciones sobre la organización del gobierno local de Cataluña ${ }^{18}$ y el Consejo de Gobiernos Locales como órgano de representación de Municipios y veguerías en las instituciones de la Generalidad (art. 85) [de donde se infiere que los entes locales no forman parte propiamente de ésta].

b) La relativa al Municipio y la autonomía municipal ${ }^{19}$, los principios de organización y funcionamiento y potestad normativa ${ }^{20}$, el principio de diferenciación ${ }^{21}$ y el régimen especial del Municipio de Barcelona (art. 89).

18 El artículo 83 dispone: i) Cataluña estructura su organización territorial básica en Municipios y Veguerías; ii) el ámbito supramunicipal está constituido, en todo caso, por las Comarcas, reguladas por una Ley del Parlamento; y iii) los demás entes supramunicipales que cree la Generalidad se fundamentan en la voluntad de colaboración y asociación de los Municipios.

19 El artículo 86 establece: i) el Municipio es el ente local básico de la organización territorial de Cataluña y el medio esencial de participación de la comunidad local en los asuntos públicos; ii) el gobierno y la administración municipales corresponden al Ayuntamiento, formado por el Alcalde o Alcaldesa y los Concejales, debiendo establecerse por Ley los requisitos que tienen que cumplirse para la aplicación del régimen de Concejo abierto; iii) la garantía al Municipio de la autonomía para el ejercicio de las competencias que tiene encomendadas y la defensa de los intereses propios de la colectividad que representa; iv) los actos y acuerdos adoptados por los Municipios no pueden ser objeto de control de oportunidad por ninguna otra Administración; v) corresponde a la Generalidad el control de la adecuación al ordenamiento jurídico de los actos y acuerdos adoptados por los Municipios y, si procede, la impugnación correspondiente ante la jurisdicción contenciosa administrativa, sin perjuicio de las acciones que el Estado pueda emprender en defensa de sus competencias; vi) los Concejales son elegidos por los vecinos de los Municipios mediante sufragio universal, igual, libre, directo y secreto; vii) las concentraciones de población que dentro de un Municipio constituyan núcleos separados pueden constituirse en entidades municipales descentralizadas a las que la Ley debe garantizar la descentralización y la capacidad suficientes para llevar a cabo las actividades y prestar los servicios de su competencia.

20 El artículo 87 determina: a) los Municipios disponen de plena capacidad de autoorganización dentro del marco de las disposiciones generales establecidas por Ley en materia de organización y funcionamiento municipal; b) los Municipios tienen derecho a asociarse con otros y a cooperar entre ellos y con otros entes públicos para ejercer sus competencias, así como para ejercer tareas de interés común, para lo cual tienen capacidad para establecer convenios y crear y participar en mancomunidades, consorcios y asociaciones, así como adoptar otras formas de actuación conjunta, no pudiendo las Leyes limitar este derecho si no es para garantizar la autonomía de los otros entes que la tienen reconocida; y c) los Municipios tienen potestad normativa, como expresión del principio democrático en que se fundamentan, en el ámbito de sus competencias y en los otros sobre los que se proyecta su autonomía.

21 Conforme al artículo 88, el principio consiste en que las Leyes que afectan al régimen jurídico, orgánico, funcional, competencial y financiero de los Municipios deben tener en cuenta necesariamente las diferentes características demográficas, geográficas, funcionales, organizativas, de dimensión y de capacidad de gestión que tienen. 


\section{c) La que tiene por objeto la Veguería ${ }^{22}$.}

\section{d) La referida a la Comarca y los demás entes locales supramunicipales ${ }^{23}$.}

También en este caso, al igual que en el Estatuto de Andalucía, hay un aspecto destacable en la regulación de la organización territorial interna: la determinación directa de competencias locales (en forma que evoca también la técnica del artículo 25.1 de la Ley 7/1985, de 2 de abril, reguladora de las bases del régimen local). A diferencia del caso de Andalucía, sin embargo, aquí la asignación competencial no se hace al escalón primero o municipal (al que solo se le garantiza, sin mayor precisión, un vago «núcleo de competencias» a ejercer con autonomía sujeta solo a control de constitucionalidad y legalidad), sino genéricamente a la organización territorial local, quedando la distribución concreta de las competencias en la disposición del legislador autonómico ${ }^{24}$. Dispone, en efecto, el artículo 84.2 que los gobiernos locales de Cataluña tienen, en todo caso, pero en los términos que determinen las Leyes, competencias propias sobre un concreto elenco de materias ${ }^{25}$.

22 Los artículos 90 y 91 disponen: 1) la veguería es i) el ámbito territorial específico para el ejercicio del gobierno intermunicipal de cooperación local y tiene personalidad jurídica propia, y ii) también la división territorial adoptada por la Generalidad para la organización territorial de sus servicios; 2) como gobierno local, tiene naturaleza territorial y goza de autonomía para la gestión de sus intereses; el gobierno y la administración autónoma de la Veguería corresponden al Consejo de Veguería, formado por el Presidente o Presidenta y por los Consejeros de Veguería; 3) el Presidente o Presidenta de Veguería es escogido por los Consejeros de Veguería de entre sus miembros; los Consejos de Veguería sustituyen a las Diputaciones; 4) la creación, modificación y supresión, así como el desarrollo del régimen jurídico de las Veguerías, se regulan por Ley del Parlamento, llevándose a cabo la alteración, en su caso, de los límites provinciales conforme a lo previsto en el artículo 141.1 de la Constitución.

23 Los artículos 92 y 93 establecen: i) la Comarca se configura como ente local con personalidad jurídica propia y está formada por Municipios para la gestión de competencias y servicios locales; ii) la creación, modificación y supresión de las Comarcas, así como el establecimiento del régimen jurídico de estos entes, se regulan por una Ley del Parlamento; iii) los demás entes locales supramunicipales se fundamentan en la voluntad de colaboración y asociación de los Municipios y en el reconocimiento de las áreas metropolitanas; y iv) la creación, modificación y supresión, así como el establecimiento del régimen jurídico de estos entes, se regulan por una Ley del Parlamento.

24 De hecho, el artículo 84.3 establece que la distribución de las responsabilidades administrativas en las materias asignadas a los gobiernos locales entre las distintas Administraciones locales debe tener en cuenta su capacidad de gestión y se rige por las Leyes aprobadas por el Parlamento, por el principio de subsidiariedad, de acuerdo con lo establecido por la Carta Europea de la Autonomía Local, por el principio de diferenciación, de acuerdo con las características que presenta la realidad municipal, y por el principio de suficiencia financiera.

25 Son las siguientes: a) la ordenación y la gestión del territorio, el urbanismo y la disciplina urbanística y la conservación y el mantenimiento de los bienes de dominio público local; b) la planificación, la programación y la gestión de vivienda pública y la participación en la planificación en suelo municipal de la vivienda de protección oficial; c) la ordenación y la prestación de servicios básicos a la comunidad; d) la regulación y la gestión de los equipamientos municipales; e) la regulación de las condiciones de seguridad en las actividades organizadas en espacios públicos y en los locales de concurrencia pública (con coordinación mediante la Junta de Seguridad de los distintos cuerpos y fuerzas presentes en el Municipio; f) la protección civil y la prevención de incendios; g) la planificación, la ordenación y la gestión de la educación infantil y la participación en el proceso de matriculación en los centros públicos y concertados del término municipal, el mantenimiento y el aprovechamiento, fuera del horario escolar, de los centros públicos y el calendario escolar; h) la circulación y los servicios de movilidad y la gestión del transporte de viajeros municipal; i) la regulación 
La regulación estatutaria de las competencias (título IV) comienza, al igual que en el Estatuto de Andalucía, por una definición tipológica, distinguiendo (en términos idénticos) las competencias exclusivas ${ }^{26}$, las compartidas ${ }^{27}$ y las ejecutivas (arts. 110, 111 y 112). Sobre esta base, el Estatuto precisa las competencias en cada caso en función de las materias, comenzando por la referida a la organización de la Administración de la Generalidad (art. 150). A esta materia siguen luego (arts. 151 y 160) las dos que aquí interesan, enunciadas, respectivamente, como:

i) «Organización territorial», respecto de la cual se determina que corresponde a la Generalidad, respetando la garantía institucional establecida por la Constitución en los artículos 140 y 141, la competencia exclusiva sobre organización territorial, que incluye en todo caso: a) la determinación, la creación, la modificación y la supresión de las entidades que configuran la organización territorial de Cataluña; b) la creación, la supresión y la alteración de los términos tanto de los Municipios como de las entidades locales de ámbito territorial inferior; la denominación, la capitalidad y los símbolos de los Municipios y de las demás entidades locales; los topónimos y la determinación de los regímenes especiales; y c) el establecimiento mediante Ley de procedimientos de relación entre las entidades locales y la población, respetando la autonomía local. Y

ii) «Régimen local», respecto del cual se establece que corresponde a la Generalidad:

1. La competencia asimismo exclusiva (respetuosa en todo caso del principio de autonomía local) sobre la parte de la materia que incluye: 1.1) en punto a organización, funcionamiento y actividad de la instancia local: a) las relaciones entre las instituciones de la Generalidad y los entes locales, así como las técnicas de organización y de relación para la cooperación y la colaboración entre los entes locales y entre éstos y la Administración de la Generalidad, incluyendo las distintas formas asociativas, mancomunadas, convencionales y consorciales; b) la determinación de las competencias y de las potestades propias de los

\footnotetext{
del establecimiento de autorizaciones y promociones de todo tipo de actividades económicas, especialmente las de carácter comercial, artesanal y turístico y fomento de la ocupación; j) la formulación y la gestión de políticas para la protección del medio ambiente y el desarrollo sostenible; k) la regulación y la gestión de los equipamientos deportivos y de ocio y promoción de actividades; 1) la regulación del establecimiento de infraestructuras de telecomunicaciones y prestación de servicios de telecomunicaciones; m) la regulación y la prestación de los servicios de atención a las personas, de los servicios sociales públicos de asistencia primaria y fomento de las políticas de acogida de los inmigrantes; y n) la regulación, la gestión y la vigilancia de las actividades y los usos que se llevan a cabo en las playas, los ríos, los lagos y la montaña.

26 Con la precisión de que en el ámbito de este tipo de competencias corresponde únicamente a la Generalidad el ejercicio de la potestad legislativa.

27 Las cuales, al igual que en el caso andaluz, operan en el marco de las bases que fije el Estado, si bien como principios o mínimo común normativo en normas con rango de Ley (excepto en los supuestos que se determinen de acuerdo con la Constitución y el Estatuto).
} 
Municipios y de los demás entes locales, en los ámbitos especificados por el artículo 84; c) el régimen de los bienes de dominio público, comunales y patrimoniales y las modalidades de prestación de los servicios públicos; d) la determinación de los órganos de gobierno de los entes locales creados por la Generalidad y el funcionamiento y régimen de adopción de acuerdos de estos órganos; y e) el régimen de los órganos complementarios de la organización de los entes locales; así como 1.2) en punto al régimen electoral: la regulación del correspondiente a los entes locales creados por la Generalidad, con la excepción de los constitucionalmente garantizados.

2. ${ }^{\circ}$ La competencia compartida sobre la parte de la materia no comprendida en el apartado anterior.

\subsubsection{Conclusiones}

Aunque la exposición de las soluciones en que se ha plasmado la evidente mayor voluntad de «interiorización» de la Administración local en este segundo grupo de Estatutos de Autonomía pudiera producir, en una primera impresión, una significativa o, si se prefiere, importante alteración de la situación establecida, un examen más atento revela inmediatamente que no hay tal en realidad.

La apariencia que provoca la aludida primera impresión deriva sólo del mayor énfasis otorgado a la regulación de la «organización territorial» de la Comunidad Autónoma y la utilización de dicha regulación como soporte para una asunción competencial diferenciada respecto de la Administración local. Pues es esta diferenciación la que posibilita, sobre la base de la tipología competencial, distinguir, de un lado, una competencia exclusiva referida al ámbito definido como más propio de la organización territorial, y, de otro lado, una competencia compartida por lo que hace al «resto del régimen local».

Debe considerarse, en efecto, que:

1. ${ }^{\circ}$ El espectro de las soluciones van:

i) Desde la valenciana, en la que:

- La regulación de la organización territorial interna presenta menor intensidad y, por ello, no hay quiebra de la continencia de la materia «régimen local», que se entiende como la integrada por todo lo relativo al «estatuto de la Administración» (más lo aludido en el art. 148.1.2. $\left.{ }^{\circ} \mathrm{CE}\right)$.

- En dicha materia (en el régimen local, en definitiva) se asume ciertamente la competencia exclusiva, pero «sin perjuicio de lo que dispone el artículo 149.1.18 CE»; 
ii) Pasando por la andaluza, en la que:

- La regulación territorial interna se dice establecida conforme no sólo al Estatuto, sino también a la legislación básica estatal y la autonómica de desarrollo.

- Se prevé que dicha regulación deba ser desarrollada por una Ley autonómica de régimen local ordenadora de las relaciones interadministrativas y las competencias locales (asegurando incluso a los Municipios un núcleo competencial respecto de materias en la disposición de la Comunidad) «en el marco de la legislación básica del Estado», sin que tampoco aquí haya propiamente quiebra de la continencia de la materia de régimen local, pues, aunque se diferencia el ámbito derivado de la organización territorial interna (perfectamente acotado por relación a los entes en la disposición de la Comunidad y distintos, por tanto, a los directamente garantizados por la Constitución, así como a la determinación de los términos de todos los entes locales y sus denominaciones), se alude a todo lo demás como lo no comprendido en él, es decir, el resto del régimen local.

- De modo que la asunción de competencia exclusiva se hace: respetando la garantía institucional de los artículos 140 y 141 CE (lo que lleva implícita la aceptación de la legislación básica estatal en cuanto aquélla que tiene por función constitucional el desarrollo de la expresada garantía en tanto que general y definitoria de un modelo de Estado), cuando se trata del ámbito de la organización territorial (en los términos antes acotados), y respetando el artículo 149.1.18 CE, cuando se trata del resto de la materia.

- Y la asunción de competencia en todo lo demás es a título de «compartida» y en el marco de la regulación general del Estado y dentro de las bases que dicte éste de acuerdo con el artículo 149.1.18 CE.

iii) Hasta la solución catalana, en la que:

- La regulación territorial interna presenta una indudable mayor intensidad, si bien cuidando de no calificar la Administración local como elemento propiamente dicho de las instituciones de autogobierno autonómico o de la Generalidad y no alcanzando, por ello, el límite de deformación o desfiguración del modelo de Estado definido desde la Constitución.

- La previsión, ciertamente y en conexión con la anterior regulación, de la distribución y, por tanto, asignación diferenciada por las Leyes autonómicas de competencias a los entes locales (todos) desde la garantía estatutaria de un elenco de competencias que no se precisa, pero en términos que permiten y llevan a la interpretación (conforme con la Constitución 
y el régimen local establecido) de que tal distribución/asignación competencial ha de producirse, a su vez, en las materias sectoriales en la disposición del legislador autonómico.

- La quiebra, en sede del ordenamiento autonómico y sobre la base de la previsión de la organización territorial interna, de la unidad de la materia de régimen local por diferenciación formal de las materias «organización territorial» y «régimen local», con consecuente asunción diferenciada de las competencias en una y otra: competencia exclusiva en la primera (comprensiva de todos los entes locales, incluidos los garantizados directamente por la Constitución, pero sólo en cuanto hace a algunos aspectos de su régimen) y parte de la segunda y competencia compartida sobre el resto de esta última.

- Pero la recuperación de la unidad de la materia de régimen local desde la perspectiva de la delimitación negativa del espacio competencial (por relación a su límite en la estatal), en la medida en que: a) la competencia exclusiva sobre la organización territorial se determina respetando la garantía institucional establecida por la Constitución en los artículos 140 y 141 (lo que significa, al igual que en el caso andaluz, la admisión implícita del juego de la legislación estatal básica llamada constitucionalmente a desarrollar la garantía institucional en cuanto general definitoria de un modelo de Estado); b) la competencia exclusiva sobre parte del régimen local se determina respetando el principio de autonomía local (lo que tiene el mismo significado que la expresión anterior); y c) la competencia es sólo compartida sobre el resto del régimen local.

2. $\quad$ Las soluciones con mayor pretensión de interiorización se establecen desde una definición tipológica de las competencias que hace que:

- Las competencias exclusivas operen siempre, con entera independencia de su formulación concreta para cada materia, bien «sin perjuicio de lo que dispone el artículo 149.1.18 CE» (Estatuto de Valencia) o «en el marco de las bases que fije el Estado» (Estatuto de Andalucía), bien confiriendo íntegramente la potestad legislativa a la Comunidad Autónoma (Estatuto de Cataluña).

La inteligencia de esta última determinación del Estatuto catalán como indicativa de que sólo el legislador autonómico puede ocupar la entera materia objeto de la competencia exclusiva (posible a partir de su tenor literal), resulta, sin embargo, desmentida por los términos concretos de la competencia específica (que, como se ha comprobado antes, incluye la referencia al respeto de la garantía y el principio constitucionales de la autonomía local), pero, en cualquier caso, porque, en otro caso, conduciría inexorablemente a la apreciación de su inconstitucionalidad por definición indebida de la competencia del Estado (desbordando la función 
constitucional del Estatuto) y ello, además, mediante una — prohibida interpretación formal, aunque sea negativa, del concepto constitucional de «bases» estatales (clave en el reparto territorial de competencias).

- Las competencias compartidas jueguen siempre, con entera independencia de su formulación concreta en cada materia, bien «en el marco de las bases que fije el Estado» (Estatuto de Valencia), bien en idéntico marco, si bien determinado solo como principios o mínimo común normativo en normas con rango de Ley, excepto en los supuestos que se determinen de acuerdo con la Constitución y el Estatuto (Estatuto de Cataluña); inciso este último que debe tenerse por no puesto en cuanto confirma la incursión del Estatuto en una prohibida interpretación formal, como única posible (siquiera sea respecto de Cataluña) del concepto constitucional de «bases» estatales.

3. De lo que se sigue que la «extracción» de la llamada organización territorial» de la materia constitucional (art. 148.1.2. ${ }^{\circ} \mathrm{CE}$ ) «régimen local» (parte específica, por las características de la Administración local) de la más amplia «bases del régimen jurídico de las Administraciones públicas» (art. 149.1.18 $\mathrm{CE}$ ) sólo es admisible como mero nomen iuris que no altera la sustancia y, consecuentemente, no hace - porque no puede hacer - a la unidad sustantiva de la referida materia y opera, en todo caso, exclusivamente al interior del ordenamiento o los ordenamientos autonómicos presididos por el o los Estatutos de Autonomía que la establezcan, pero en nada afecta, por ello, a la unidad sustantiva y formal de la materia en sede constitucional, a efectos del reparto territorial de competencias y, por tanto, al ordenamiento estatal en su función de desarrollo del principio y la garantía institucional de la autonomía local como elementos del modelo de Estado establecido por la norma fundamental (ciertamente flexible, pero existente). Con entera independencia, pues, de que al interior de algunas Comunidades Autónomas la «continencia» (por emplear este gráfico concepto procesal) del régimen local se quiebre en varios y diferenciados desarrollos legislativos (relativos a la organización territorial interna y el régimen local), el legislador estatal podrá y deberá continuar estableciendo las bases del entero régimen local entendido como materia constitucional dotada de lógica propia y comprensiva de todo cuanto exija el desarrollo del principio y la garantía institucionales de la autonomía local para la definición general del modelo de Estado constituido (con entera independencia de que su objeto este formalmente definido como régimen local u organización territorial en los Estatutos de Autonomía).

4. ${ }^{\circ} \quad$ La apuntada diferenciación estatutaria formal de la materia «organización territorial» persigue, en definitiva, no ya condicionar el alcance de las bases estatales en materia de régimen local prefijando su carácter como principios o mínimo común denominador, sino fijar a las mismas (determinando negativamente su espacio propio) un «suelo» mediante la acotación, a su amparo, de una parte de aquél régimen como perteneciente a la competencia exclusiva de 
la correspondiente Comunidad Autónoma. Pero la exclusividad de la competencia nada dice de su extensión material; expresa sólo la plena capacidad de decisión del legislador correspondiente sobre el ámbito que efectivamente cubra. Y, con independencia incluso de los argumentos esgrimibles - y en parte ya expuestos - para dudar de su constitucionalidad, la apuntada operación no consigue de todas maneras una definición mejor (siquiera sea negativa) que la actual de la extensión y el alcance de las bases, pues debe inevitablemente dejar a salvo el principio y la garantía constitucionales de la autonomía local, cuya condición de elementos generales del modelo territorial del Estado constituido es la que justifica cabalmente la entrega al legislador estatal - como competencia - de su desarrollo en términos de bases del régimen de la Administración local. Con la consecuencia de que el establecimiento del aludido «suelo» estatutario deja intacta (como tal) dicha competencia básica estatal.

Esta consecuencia se da incluso admitiendo la plena constitucionalidad de las determinaciones organizativas de los Estatutos de Autonomía reformados con mayor pretensión de «interiorización» de la Administración local, pues según la doctrina sentada por la STC 247/2007, de 12 de diciembre (establecida con ocasión del examen de uno de ellos), i) si bien el legislador estatutario puede incluso interpretar la Constitución sometiéndose a los mismos criterios que todo legislador, ha de hacerlo - dada su función y su doble carácter de norma estatal y autonómica - partiendo de una interrelación de "especial amplitud", y ii) aunque, en cuanto norma estatal, puede atribuir competencias a la correspondiente Comunidad Autónoma y, al hacerlo, delimitar competencias, incidiendo en el alcance de las del Estado, tal operación debe ser cumplida sólo para favorecer la mayor concreción de las competencias autonómicas y sin quebrantar el marco del artículo 149.1 CE, desnaturalizando el contenido propio de cada materia, ni impedir el despliegue completo de las funciones propias de la competencia estatal ex artículo 149.1 CE.

Concluyendo cabe afirmar que, incluso en la hipótesis más extrema derivada de la pretensión estatutaria por innovar la situación decantada en punto a la Administración local, permanece incólume la competencia del legislador estatal para definir las bases del régimen local en toda su extensión; afirmación, que debe entenderse hecha sin entrar ahora en el carácter y el alcance que deban tener dichas bases, que es cuestión diferente. En la expuesta hipótesis la pretensión estatutaria puede reconducirse en último término, en efecto, a la acuñación como «organización territorial» (interna) de la correspondiente Comunidad Autónoma de la parte del régimen local que cabría calificar de «más organizativa» para propiciar la cobertura de su «interiorización» en el genérico poder de autoorganización que implica siempre el ejercicio del derecho a la autonomía a través de la norma «Estatuto de Autonomía». Al margen ya incluso de los argumentos que cabe oponer a tal cobertura y en parte ya expuestos, el poder de organización actuado mediante la aprobación o innovación de los Estatutos de Autonomía - aún considerando que, por la intervención aprobatoria del Estado 
en sentido estricto, no lo sea sólo en calidad de autoorganización autonómicano es, sin embargo, capaz de otorgar la aludida cobertura. Y ello, por las siguientes razones:

a) Conforme al artículo 147.2 CE, el Estatuto de Autonomía es, en su contenido prescriptivo constitucionalmente preceptivo (con entera independencia de que pueda tener o no otros contenidos), una norma organizativa circunscrita a las instituciones del autogobierno autonómico, por lo que la reserva constitucional establecida en su beneficio en cuanto Ley orgánica (iniciativa, procedimiento y competencias de aprobación, con consecuente posición específica y «resistente» en el ordenamiento total) solo es predicable, con carácter estricto, de dicho contenido.

b) Aunque así no fuera, el Estatuto de Autonomía, por su objeto y función constitucionales, se inscribe completamente en el círculo de intereses del autogobierno de la correspondiente comunidad territorial conforme al artículo 137 CE; círculo éste que, por definición, se inscribe, a su vez, en el más amplio de la comunidad constituida en su conjunto. Lo que significa que la definición de la estructura territorial total del Estado no pertenece a aquel círculo y queda, por ello, completamente fuera de la disposición de las comunidades territoriales, o, en otros términos, que no puede integrar el objeto de una decisión organizativa - como la estatutaria - tomada por y para una parte autónoma de aquella comunidad total. Ni siquiera un supuesto poder de organización no precisado de identificación en título competencial material alguno podría ser actuado, pues, en sede estatutaria para definir elementos pertenecientes a la estructura del Estado como un todo. Y el principio y la garantía institucionales de la autonomía local son elementos de tal estructura ex artículo 137 CE.

\section{La determinación constitucional del título competencial del Estado en sentido estricto en materia de régimen local}

El planteamiento de los Estatutos de Autonomía renovados con mayor pretensión de «interiorización» de la Administración Local descansa, como se ha visto, en una igual renovación del título competencial constitucional del Estado respecto de dicha Administración. A este respecto, cabría resumir los argumentos a favor de tal renovación así:

1. $\quad$ No estando, en la Constitución, expresamente distribuido el poder (la potestad) de organización, debe suponerse, sin embargo, la existencia de éste a lo largo de toda la estructura del Estado constituido, como, de otro lado, revela la comprensión por la autonomía - conforme a la doctrina constitucional y en cada instancia territorial - de la potestad de autoorganización. De esta comprobación se extrae la consecuencia 
de que la «organización» no es tanto una materia-título competencial específico cuanto el objeto sin más del referido poder.

2. ${ }^{\circ}$ Supuesto ese poder de organización y siendo la Administración local, en cuanto organización, parte de su objeto propio, ésta en modo alguno lo es de una de las materias del sistema constitucional de distribución territorial del poder constituido, por lo que el desarrollo constitucional de los artículos 137, 140 y $141 \mathrm{CE}$ puede producirse en ejercicio de aquél y al margen de los títulos competenciales enunciados en los artículos 148 y 149 CE. De donde se sigue que los Estatutos de Autonomía, en tanto que normas de organización, pueden legítimamente adoptar decisiones sobre la organización de la Administración local. Lo que no afecta, así, al reparto competencial sobre la base de las correspondientes «materias» sustantivas y, en particular, de la de régimen local en términos de bases-desarrollo legislativo.

A esta interpretación constitucional subyace la idea de que la expresión constitucional «gobierno y administración» tiene un contenido más amplio que la asimismo constitucional de «Administración local» por aludir a la entera instancia territorial dotada de una autonomía cuya sustancia desborda la propia de la Administración según el modelo mismo de la Constitución. Una cosa sería, pues, la organización de la instancia territorial autónoma local y otra distinta el régimen jurídico de la Administración local. Ocurre que, careciendo la instancia local de potestad legislativa (al tratarse de una autonomía «en el marco de la Ley»), su organización no puede producirse primariamente - a diferencia de la autonómica - en ejercicio del propio poder de autoorganización, debiendo ser fruto de decisión legislativa heterónoma al deber desarrollarse él mismo también en el marco de la Ley. Como quiera que la organización de las entidades locales necesarias objeto de directa garantía constitucional es parte del desarrollo del modelo general de la organización territorial del Estado y excede, por su objeto, del círculo de intereses de la autonomía reconocida a las Comunidades Autónomas, la referida Ley no puede ser otra que:

- La Ley estatal, por lo que hace a los Municipios y las Provincias (arts. 140 y 141, en relación con el art. 137, CE), como vendría así a confirmar la alusión por el artículo 148.1.3 CE a una legislación sobre régimen local autorizatoria de transferencias a las Comunidades Autónomas de competencias sobre las entidades locales pertenecientes a la Administración General del Estado (alusión aislada en el contexto del bloque formado por los artículos 148.1 y 149.1 CE que adquiriría así pleno sentido).

- Las Leyes autonómicas, por lo que hace a las restantes entidades locales inscritas en su propio ordenamiento.

Para facilitar su admisión, semejante interpretación podría ciertamente perseguirse a los solos efectos de diferenciar, al igual que sucede para la instancia 
autonómica, entre la organización del Gobierno local y el régimen de la Administración local y, con ello, la regulación del primero sobre la base de la nuda potestad de organización ex artículo $137 \mathrm{CE}$ y la del segundo conforme a la lógica del régimen jurídico de las Administraciones públicas ex artículo 149.1.18 CE. Pero, además de que, en todo caso, muy poco, por decir nada, se conseguiría con ello, lo cierto es que el planteamiento tropieza con obstáculos insalvables y no puede ser aceptado como válido. Las razones son contundentes:

- Por de pronto, aunque sea cierto que el poder de organización forma parte del poder constituido en la medida en que ya la «constitución» del Estado es, ella misma, ejercicio de dicho poder (razón por la cual el artículo 1.1 CE puede decir que España «se constituye» en un Estado social y democrático de Derecho) y, por ello, esté implícito en cualquiera de los diferenciados «poderes» constituidos (de ahí justamente la doctrina de que la autoorganización forma parte de la autonomía reconocida constitucionalmente), no por ello cabe afirmar que no esté distribuido o repartido. Cabalmente su condición implícita o «inherente» determina necesariamente su distribución, pues tiene un carácter formal e instrumental respecto de las responsabilidades y funciones referidas a la realización constante del orden constitucional y, por tanto, sólo lo tiene aquél que cuenta con un poder sustantivo constitucionalmente asignado, es decir, repartido, territorial y funcionalmente. Y ello es así, porque, en cuanto poder formal capaz de proyectarse sobre cualquier tarea (al igual que el de expropiar o sancionar), está al servicio de ésta, es decir, de cualquier cometido en cualquier materia. Dicho en otros términos: el poder de organización acompaña necesariamente a toda institucionalización de un poder público y su responsabilización con determinadas tareas sustantivas, porque sería absurdo que ambas decisiones no implicaran la ulterior habilitación del poder instituido para adoptar cuantas medidas fueran instrumentalmente necesarias para hacer factible el cumplimiento de las tareas asignadas en los términos en los que lo han sido. Una mayor justificación de este incontestable fundamento y del consecuente carácter del poder organizativo desbordaría absolutamente el marco de este trabajo ${ }^{28}$.

Por tanto, la distribución del poder de organización acompaña a la del poder sustantivo o para funciones o tareas determinadas o, lo que es igual, coincide con ella. Está, pues, constitucionalmente repartido (siguiendo fielmente la distribución por materias sustantivas). Esto es claro, en el caso de la división, es decir, el reparto funcional (legislativo/ejecutivo) del poder en el seno de una misma instancia-ordenamiento territorial, como demuestra sin más la institución de la reserva de Ley. Pero lo es igualmente en la dimensión territorial, pues precisamente la autoorganización ínsita en la autonomía expresa el reparto te-

\footnotetext{
28 Procede, por ello, remitir in totum a mi reciente trabajo sobre tal cuestión, en el que podrá encontrarse una justificación pormenorizada a la afirmación que se hace en el texto: L. Parejo Alfonso, Organización y poder de organización. Las potestades organizatoria y reglamentaria del complejo orgánico-funcional Gobierno y Administración, Ed. Iustel, Madrid 2009.
} 
rritorial del poder de organización sobre los elementos de la estructura territorial del Estado, en la medida en que el poder constituido se articula — en virtud del principio de descentralización político-administrativa - en diversas instancias territoriales de poder justamente para el cumplimiento del total de fines $\mathrm{y}$, por tanto, cometidos o tareas del Estado en su conjunto. De lo que se sigue - como tempranamente puso de manifiesto S. Muñoz Machado ${ }^{29}$ - la compleción del universo de materias y títulos de acción en ellas contemplado en los artículos 148 y 149 CE en la medida en que estos preceptos traducen en competencias el total de intereses públicos en que es capaz de manifestarse (ahora y en el futuro) el interés general y las reparten en función de los círculos territoriales de intereses correspondientes a la organización territorial del Estado según el artículo $137 \mathrm{CE}$.

Todo lo cual abunda a favor de la posición del Tribunal Constitucional de que - salvo excepciones derivadas de atribuciones inequívocas y expresas en otros preceptos - el bloque formado por los artículos 148 y 149 CE agota el reparto territorial del poder público constituido.

- La organización no ofrece ciertamente perfiles nítidos, pero en todo caso cabe decir, de un lado, que no se agota en decisiones simples (se refiere más bien a un proceso complejo), y, de otro lado, que comprende tanto el campo «interno» del poder público (creación, estructuración, puesta en marcha, dotación de medios, etc...), como el «externo» o relativo a la acción de éste y ello en una interacción recíproca específica (a través justamente de la dotación con potestades, competencias y atribuciones concretas en función de fines y cometidos).

Ello significa que, cuando se despliega respecto del propio poder público es siempre y en parte (diversa) heterónoma (decisión de un poder ajeno con competencia para organizar otro poder: el constituyente respecto de todos los constituidos; y el legislador respecto del ejecutivo o de la Administración local, por ejemplo) y autónoma (decisión del poder de que se trate sobre sí mismo en función de sus tareas). No otra es la causa por la que el reconocimiento de autonomía supone reparto del poder de organización.

Pero esta diferenciación de «dentro» (del poder institucionalizado) y «fuera» (fines y cometidos del poder) es de orden lógico y no necesaria, presentándose ambas dimensiones imbricadas en la realidad, por lo que en modo alguno otorga soporte a su diferenciación como «materias» distintas y desde luego nunca si la Constitución, cual sucede con la Administración local, ha definido una materia que, por su peculiaridad, incorpora - como su núcleo mismo - la organización en sentido estricto (como resulta de lo ya argumentado con anterioridad).

29 Ya en 1982 y en su conocida obra «Derecho público de las Comunidades Autónomas», Ed. Cívitas (actualizada en 2008 en edición de Iustel). 
Que esto es así se deduce sin dificultad precisamente del artículo 148.1.2 $\mathrm{CE}$, en el que queda claro que el constituyente i) no se ha «olvidado» - a la hora del reparto territorial de competencias - del desarrollo constitucional en punto a la Administración local; y ii) ha querido y quiere - con todas las deficiencias técnicas que se quiera - la existencia de una materia de «régimen local» y su ocupación primaria por el legislador estatal (sin precisión aquí del alcance de ésta). La asunción estatutaria de la competencia sobre la organización local en calidad de organización territorial interna, mediante el expediente - en si mismo más que discutible - de «creación» nominal de una nueva materia, no puede ampararse, pues, ni en un supuesto poder de organización de lógica propia (ajena al reparto constitucional de funciones sobre materias), ni en el inciso inicial del artículo 149.3 CE. Lo primero, porque - prescindiendo incluso de la cuestión (y, por tanto, admitiéndola) de si los Estatutos de Autonomía pueden válidamente, siendo, como son, normas singulares por su objeto y procedimiento de aprobación y reforma, «prefigurar» y «rigidificar» en sus respectivos ordenamientos (condicionándolo en calidad de parte integrante del bloque de la constitucionalidad) el desarrollo lógico de la pieza basal del modelo general de la organización territorial del Estado - la correspondiente normación estatutaria nunca será fruto del mero poder de organización (al no alcanzar para ello el que deriva de la potestad de autoorganización) y será siempre, en términos constitucionales y por su objeto, regulación de «régimen local» que debe enmarcarse - por exigencia de la lógica de la organización territorial del Estado, incluso desde el punto de vista exclusivamente organizativo - en la legislación básica estatal de dicho régimen. Y lo segundo, porque la cláusula residual y abierta del artículo 149.3 CE nunca puede otorgar cobertura a un desapoderamiento de funciones constitucionalmente otorgadas al Estado en sentido estricto, sea por la vía del poder o potestad de organización, sea por la más procedente de la competencia referida a una determinada materia.

- No porque, en pura hipótesis, el régimen local se agote en la organización de la Administración local de relevancia constitucional podrían las Comunidades Autónomas asumir dicha organización como asunto de la propia competencia sobre la base del poder de organización del que constituyen ejercicio las normas estatutarias (sobre la base del llamado principio dispositivo). Ese poder de organización deriva, en efecto, de la autonomía constitucionalmente reconocida y consiste cabalmente en la «autoorganización», lo que, conforme al artículo 147.2 CE incluye solo las instituciones propias, de las que en rigor no forma parte la Administración local. Y aún admitiendo que alguna capacidad de decisión al respecto pudiera derivar de la autoorganización autonómica (lo que ciertamente es plausible, al ser el círculo de intereses de la comunidad autónoma más amplio que el de las entidades locales comprendidas en su territorio), dicha capacidad nunca podría alcanzar a los elementos materialmente unitarios de la organización local garantizada constitucionalmente en tanto que necesariamente inscritos - en tanto que partes integrantes del modelo general 
del Estado constituido como un todo - en el círculo de los intereses propio de la comunidad total constituida. De lo que se sigue que, por el mismo razonamiento, la decisión sobre ellos pertenece, por definición, al poder de organización perteneciente a la «autoorganización» de las instituciones generales representativas de la comunidad total constituida para la continuación del proceso de autoorganización en sede del desarrollo constitucional. Por lo que la asunción estatutaria de la competencia exclusiva sobre la entera organización del gobierno y la administración local (desplazando cualesquiera bases estatales) tampoco puede encontrar amparo en el genérico poder de organización.

- Conclusión ésta que resulta corroborada por el hecho de que, en otro caso, se destruiría la universalidad y, por tanto, la compleción del sistema constitucional de distribución territorial de competencias tal como éste resulta de los artículos 148 y 149 CE, que podría comprender así no sólo otros preceptos de objeto no directamente competencial (lo que ya ha sido rechazado como regla general por el Tribunal Constitucional), sino incluso reglas supuestamente implícitas deducidas interpretativamente del orden constitucional (lo que parece ya completamente excesivo).

- La organización del gobierno y la administración local (cuando menos de las entidades garantizadas constitucionalmente) es, pues y a efectos del desarrollo constitucional del modelo territorial del Estado constituido, un ámbito que forma parte de la materia «régimen local» y esta materia es, necesariamente (por la peculiaridad de dicho modelo de Estado), «bifronte» en el sentido de que en ella tienen algo que decir las dos instancias territoriales superiores. Carácter «bifronte» éste, que está muy lejos de constituir una anormalidad de la materia y que se da también, sin ir más lejos, en la de «régimen jurídico de las Administraciones públicas» y respecto de las Administraciones directas de las Comunidades Autónomas que, éstas sí, son incluso instituciones propias del autogobierno de tales Comunidades ${ }^{30}$. Por lo que tal carácter «bifronte», que

\footnotetext{
30 En este sentido es clara la STC 50/1999, de 6 de abril, cuando dice:

«...Hemos declarado que «conformar libremente la estructura orgánica de su aparato administrativo» (STC 165/1986, fundamento jurídico $6 .^{\circ}$ ), establecer cuáles son «los órganos e instituciones» que configuran las respectivas Administraciones (STC 35/1982, fundamento jurídico 2. ${ }^{\circ}$ ), son decisiones que corresponden únicamente a las Comunidades Autónomas y, en consecuencia, el Estado debe abstenerse de cualquier intervención en este ámbito (STC 227/1988 y «a sensu contrario» STC 13/1988).
}

Sin embargo también hemos reiterado desde la STC 32/1981 (fundamento jurídico 6. ${ }^{\circ}$, que fuera de este ámbito de actividad autonómica exclusiva, el Estado puede establecer, desde la competencia sobre bases del régimen jurídico de las Administraciones públicas del art. 149.1.18 CE, principios y reglas básicas sobre aspectos organizativos y de funcionamiento de todas las Administraciones públicas. Esto significa que, en palabras de la STC 227/1988, «la potestad organizatoria (autonómica) (...) para determinar el régimen jurídico de la organización y funcionamiento» de su propia Administración, no tiene carácter exclusivo, sino que debe respetar y, en su caso, desarrollar las bases establecidas por el Estado. En definitiva, salvo en lo relativo a la creación de la propia Administración, la potestad de autoorganización, incluso en lo que afecta a los aspectos de organización interna y de funcionamiento, no puede incluirse en la competencia exclusiva de autoorganización de las Comunidades Autónomas, aunque ciertamente, como veremos de inmediato, no cabe atribuir a 
alude únicamente al ordinario fenómeno de la concurrencia (ordenada por el principio de la competencia) de las legislaciones estatal y autonómica en la regulación acabada de una materia, es indiferente (en cuanto argumento) para el concreto reparto de competencias entre el Estado en sentido estricto y las Comunidades Autónomas en la materia de régimen local.

De lo hasta aquí argumentado resulta con toda naturalidad la corrección de la jurisprudencia constitucional sentada, entre otras, por las SsTC 32/1981, de 28 de julio; 76/1983, de 5 de agosto; 27/1987, de 27 de febrero; 214/1989, de 21 de diciembre y 240/2006, 20 de julio, y que afirma con toda rotundidad la conexión entre la garantía constitucional de la autonomía local (arts. 137, 141 y $142 \mathrm{CE}$ ) y la competencia que ostenta el Estado sobre «las bases del régimen jurídico de las Administraciones públicas» (art. 149.1.18 CE), de tal forma que debe ser el legislador estatal, con carácter general y para todo tipo de materias, el que fije unos principios o bases relativos a los aspectos institucionales (organizativos y funcionales) y a las competencias locales, con cobertura en el art. 149.1.18 CE. Este debe entenderse, pues, que es el título y la cobertura constitucionales de una legislación estatal básica y, por tanto, general sobre el gobierno y la administración local.

Importa destacar que la conexión así establecida por el Tribunal Constitucional es necesaria y no meramente posible (en el sentido de su mera constitucionalidad, pero sin excluir otras soluciones igualmente constitucionales), como sostiene alguna doctrina.

Y es necesaria, por constitucionalmente obligada en función de la interpretación sistemática de los artículos 148 y 149 CE en tanto que sistema de distribución territorial de competencias: previendo el artículo 148.1 una legislación estatal de régimen local y formando parte las entidades locales en su conjunto (cualesquiera que éstas sean: garantizadas o no directamente por la CE) del poder público administrativo constituido, la regulación de aquéllas ha de formar parte también de la materia «régimen jurídico de las Administraciones públicas» (inclusiva del conjunto de las Administraciones, es decir, de todo el poder publico administrativo constituido) en la que el artículo 149.1.18 CE reserva al Estado en sentido estricto la legislación básica. Frente a esta interpretación se ha pretendido aducir que al menos las entidades locales constitucionalmente garantizadas son algo más que «administración» en tanto que la Constitución emplea, a propósito de ellas, la expresión «gobierno y administración». Esta expresión, alusiva exclusivamente a la economía decisional interna de las correspondientes instituciones, carece de entidad para otorgar soporte al reconocimiento a las entidades locales de una cualidad superior o distinta a la propia de una Administración pública. Basta con decir que su empleo es abso-

las bases estatales la misma extensión e intensidad cuando se refieren a aspectos meramente organizativos internos que no afectan directamente a la actividad externa de la Administración y a los administrados, que en aquellos aspectos en los que se da esta afectación...». 
lutamente generalizado para designar el sistema decisional de todo tipo de organizaciones, tanto de Derecho público, como de Derecho privado. Cuestión distinta es que la sustancia de la gestión de los asuntos públicos encomendados a las entidades locales (desde luego en el caso de las garantizadas constitucionalmente) sea política. Ocurre, empero, que las decisiones adoptadas en el curso de tal gestión tienen, por prescripción constitucional, un alcance solo administrativo, justamente por producirse enteramente (incluso conforme a la Carta Europea de la Autonomía Local: art. 3.1) «en el marco de la Ley». Lo cual implica que las decisiones derivadas de la autodisposición sobre sí misma con la que cuenta la entidad local nunca pueden alcanzar el carácter, el rango y la fuerza propios de la Ley formal y sí sólo de las normas reglamentarias.

Tampoco es aceptable sin ulterior matización la tesis de que, aún siendo el precisado en el artículo 149.1.18 CE el título de la competencia legislativa estatal en la materia, la imprecisión del concepto «bases» comporte un margen de libre configuración para el legislador estatal tan amplio que va desde simplemente lo común a todas las Administraciones públicas hasta el diseño peculiar de lo básico para la Administración local (como, por ejemplo, sucede con el contenido de la actual Ley 7/1985, de 2 de abril, de bases del régimen local). No pudiendo negarse la existencia de un margen a favor del legislador en la configuración legal básica del régimen local, la matización obligada deriva de la peculiaridad de la Administración en el seno del poder público administrativo.

Conforme a la Constitución, en efecto, ese poder (la total constelación de organizaciones de administración pública) aparece articulado a partir y sobre la base de tres Administraciones territoriales ${ }^{31}$ necesarias, constitutivas, así, del núcleo policéntrico de aquella constelación. Pues bien, en este núcleo, si las Administraciones directas de las dos instancias territoriales superiores tienen naturaleza institucional-burocrática y su legitimación fundamental viene dada en el doble plano objetivo de la legalidad y la eficacia en la actuación, siendo la democrática derivada y, por tanto, indirecta (conseguida a través de la dependencia de y dirección por el Gobierno, que, a su vez, es responsable ante el correspondiente Parlamento), la Administración local no tiene en común con ellas (plenamente o en los mismos términos) ni siquiera la nota de la territorialidad, singularizándose de ellas por relación a sus siguientes características:

- Única instancia territorial del poder público administrativo a través de la cual se ejercita el derecho fundamental ciudadano (reconocido en el artículo 23.1 CE) de participar en los asuntos públicos de orden administrativo, directamente (caso del Concejo abierto) o por medio de representantes libremente elegidos en elecciones periódicas por sufragio

\footnotetext{
31 Sin perjuicio de la trascendencia de su diferenciación interna en Municipios y Provincias, la instancia local se considera aquí - a los exclusivos efectos de la argumentación que ahora se desarrolla en el textoen bloque o como un todo, tal como luce en la rúbrica del Capítulo II «De la Administración local» del título VII de la Constitución.
} 
universal (en los Municipios en primer grado y en las Diputaciones provinciales en segundo grado).

- El gobierno y la administración local lo es de la corporación territorial misma (con lo que la territorialidad aquí supone más que universalidad de fines con relación a un territorio; implica la condición de miembros de la organización, es decir, de la corporación de todos los residentes en el territorio; de ahí la importancia tradicional de la vecindad) y se confiere, así, bien directamente a los miembros de la colectividad territorial institucionalizada (la corporación local correspondiente), bien a sus representantes, para que se produzca y desarrolle, así, en régimen de autonomía, es decir, bajo la propia responsabilidad y, por ello, de una verdadera «autoadministración».

- La fuente de legitimación primaria y directa es, por tanto, de origen: la democrática, que cobra así el mismo protagonismo que la objetiva generada por la actuación conforme a Derecho y la eficacia.

Por estas características peculiares, de la que es derivable la preferencia de la Administración local en la articulación del poder público administrativo conforme al principio de descentralización proclamado en el artículo 103.1 CE, la Administración local debe ser objeto de una regulación básica específica, cabalmente la del régimen local.

Esa regulación básica podrá estar contenida en una Ley de régimen local o, por el contrario, inserta en la Ley básica de régimen jurídico de las Administraciones públicas, lo que dependerá, en definitiva, de una opción de técnica legislativa. Pero lo que no es objeto lícito de tal opción es la especificidad - en cuanto a su contenido y alcance - y, por tanto, la diferenciación de dicha regulación. Lo impide la peculiaridad constitucional de la Administración local.

\section{EL CONTENIDO Y ALCANCE DE LA LEGISLACIÓN BÁSICA DE RÉGIMEN LOCAL}

\section{Consideraciones generales}

La existencia de una legislación estatal básica de régimen local, en el seno o no de la legislación estatal básica de régimen jurídico de las Administraciones públicas, es, pues y por las razones expuestas en el apartado anterior, un imperativo del desarrollo constitucional del modelo territorial del Estado constituido. Pero, como se ha dicho ya también, en el cumplimiento de esta exigencia constitucional goza el legislador de un cierto margen de configuración, lo que es consustancial al desarrollo constitucional y en modo alguno una anormalidad de la remisión a las bases de régimen local. Al día de hoy: 
- Es clara, por haber superado el examen del Tribunal Constitucional (STC 214/1989, de 21 de diciembre), la constitucionalidad de la configuración del régimen básico plasmada en la Ley 7/1985, de 2 de abril (más dudosa podría ser, por su detallismo, la de su ampliación con el régimen de las llamadas grandes poblaciones introducido la Ley de 2003).

- Pero igualmente clara es la aceptación posterior por el mismo legislador estatal (al aprobar las correspondientes Leyes orgánicas) de las consecuencias derivables (para el régimen local básico) de las recientes regulaciones por las reformas estatutarias más extremas de las correspondientes organizaciones territoriales internas y sus proyecciones competenciales.

En consecuencia, el legislador estatal ordinario que pretenda la renovación de la legislación básica de régimen local (ahora bajo la denominación, en su caso, de gobierno y administración local) debería, para ser consecuente y considerando la doctrina sentada en la STC 247/2007, de 12 de diciembre, atender debidamente la incidencia legítima en la delimitación de la competencia estatal de las aludidas reformas estatutarias, naturalmente excluyendo las que lesionen indebidamente (por desnaturalizarlo) el espacio propio, constitucionalmente, de dicha competencia estatal. Esto quiere decir, más que probablemente, que la nueva legislación habría de responder, en las actuales circunstancias y empleando el margen de configuración legal disponible, a una interpretación estricta de lo básico en esta materia.

Cobra renovada importancia, así, la interpretación que de las bases del régimen local tiene establecida la jurisprudencia constitucional; interpretación que, conviene dejarlo adelantado, ha evolucionado a lo largo del tiempo.

El punto de partida cabe situarlo en la STC 214/1989, de 21 de diciembre, que, en lo sustancial, avaló el contenido prescriptivo de la vigente Ley 7/1985, de 2 de abril (en su versión originaria, es decir, antes de sus ulteriores reformas y ampliaciones parciales). Afirmada allí la función de desarrollo constitucional de la garantía institucional de la autonomía local que cumple dicha Ley, los pronunciamientos inmediatamente posteriores la incluyen ya, con normalidad, en el «bloque de la constitucionalidad» desde el que deben medirse y valorarse, en particular, las Leyes autonómicas de desarrollo. Así resulta de pronunciamientos anteriores y posteriores a la aludida Sentencia (SsTC $27 / 1987,27$ de febrero; 109/1989, de 21 de mayo; 11/1999, de 11 de febrero; y 159/2001, de 5 de julio $^{32}$ ), si bien con la matización que precisan las SsTC 156/1995, de 26 de

32 La primera de ellas y recogiendo otros pronunciamientos anteriores, sostiene que:

«...En cuanto a la legislación estatal, las normas básicas que han de tomarse en consideración en la resolución del presente recurso son las contenidas en la Ley 7/1985, de 2 de abril, reguladora de las Bases de Régimen Local, actualmente vigente, puesto que, como declara la sentencia 87/1985, de 16 de julio, y más recientemente la 137/1986, de 6 de noviembre, reiterando lo que viene siendo criterio de este Tribunal, «en el recur- 
octubre; 163/1995, de 8 de noviembre; y 252/2005, 11 de octubre: en el caso de duda de constitucionalidad que requiera del contraste entre la normativa básica y la de desarrollo para determinar si esta última es o no conforme con la Constitución, ha de verificarse la constitucionalidad misma de la norma básica antes de utilizarla como parámetro indirecto de la constitucionalidad de la norma de desarrollo.

Sin embargo, a partir de la STC 159/2001, de 5 de julio, se va modulando esta doctrina hasta culminar por ahora - en la STC 240/2006, de 20 de julio y tras la introducción del conflicto en defensa de la autonomía local - en los siguientes y más restrictivos pronunciamientos:

- La jurisprudencia previamente establecida no permite extraer conclusiones definitivas sobre el valor de la Ley de las bases del régimen local como canon de enjuiciamiento y en todo caso no son trasladables al conflicto en defensa de la autonomía local.

- Por haber recaído en procesos de declaración de inconstitucionalidad (en los cuales se enjuiciaba la conformidad o disconformidad de Leyes autonómicas, o de la misma Ley de las bases del régimen local, con la Constitución esencialmente por motivos competenciales), dicha jurisprudencia ha podido acudir a la idea de «bloque de constitucionalidad» (art. 28.1 LOTC) para decidir si una concreta disposición se adecua o no al orden constitucional de distribución de competencias en materia de «régimen local», entendido como «régimen jurídico de las Administraciones Locales». Pero esto último no equivale a «autonomía local, porque los imperativos constitucionales derivados del art. $137 \mathrm{CE}$, por un lado, y del 149.1.18 CE, por otro,_no son coextensos.

- Aunque la referida jurisprudencia ha reconocido puntualmente la singular y específica naturaleza y posición de la Ley de las bases del régimen local en el ordenamiento jurídico (así en STC 259/1988, de 22 de diciembre), de ella no cabe deducir que dicha Ley constituya siempre canon de validez de la Ley, estatal o autonómica, a la hora de enjuiciar normas que desarrollen aspectos concretos de la autonomía local. De la Ley estatal no lo constituye porque la Ley de las bases del régimen local, más allá de la referida naturaleza singular, y de su carácter básico ex art.

\footnotetext{
so abstracto no se fiscaliza si el legislador se atuvo o no, en el momento de legislar, a los límites que sobre él pesaban, sino más bien, si su producto normativo se atempera, en el momento del examen jurisdiccional, a tales límites y condiciones».

Todos estos preceptos estatutarios y legales, interpretados conjunta y sistemáticamente y de conformidad con la Constitución, son los que deben tomarse en consideración como parámetros de la legitimidad constitucional de los preceptos impugnados de la Ley 2/1983 de la Generalidad Valenciana, de tal manera que su infracción por estos últimos determinaría su nulidad por vulneración del bloque de constitucionalidad aplicable a la materia de que se trata» (la cursiva es mía).
} 
149.1.18 CE, no ocupa en nuestro ordenamiento una posición distinta a las demás Leyes ordinarias del Estado, que pueden por tanto establecer disposiciones contrarias a la Ley de las bases del régimen local, las cuales deberán ser consideradas modificaciones legislativas pero no Leyes inconstitucionales. Y de la Ley autonómica sólo podría ser canon de validez en aquellos aspectos enraizables directamente en los arts. 137, 140 y 141 CE, de cuyo contenido no representen más que exteriorizaciones o manifestaciones, pues sólo ellos forman parte del contenido de la autonomía local constitucionalmente garantizada, mientras que los que se refieran a aspectos secundarios o no expresivos de ese núcleo esencial en el que consiste la garantía institucional y que se incardinan, desde el punto de vista competencial, en el art. 149.1.18 CE, tienen una distinta naturaleza desde el punto de vista constitucional y ordinamental.

- En conclusión: el canon que debe aplicarse para resolver los conflictos en defensa de la autonomía local promovidos frente a Leyes estatales se ciñe a los preceptos constitucionales (arts. 137, 140 y 141 CE) que establecen el «contenido mínimo» que protege la garantía institucional y que deben ser considerados, así, definitorios de «los elementos esenciales»o del «núcleo primario» del autogobierno de los entes locales territoriales. Y ello, porque, no habiendo el constituyente predeterminado el contenido concreto de la autonomía local, el legislador constitucionalmente habilitado para regular materias de las que sea razonable afirmar que formen parte de ese núcleo indisponible puede, ciertamente, ejercer en uno u otro sentido su libertad inicial de configuración, pero no podrá hacerlo de manera que establezca un contenido de la autonomía local incompatible con el marco general perfilado en los arts. 137, 140 y $141 \mathrm{CE}$. So pena de incurrir en inconstitucionalidad por vulneración de la garantía institucional de la autonomía local, el legislador tiene vedada toda regulación de la capacidad decisoria de los entes locales respecto de las materias de su interés que se sitúe por debajo de ese umbral mínimo que les garantiza su participación efectiva en los asuntos que les atañen y, por consiguiente, su existencia como reales instituciones de autogobierno.

Aunque no coincidan los planteamientos de las reformas estatutarias (en especial la «interiorización» de la organización local y su incidencia en el plano competencial) y la jurisprudencia constitucional sintetizada, ésta última permite su compatibilización al precisar la conclusión alcanzada en el apartado anterior sobre el título competencial estatal en la materia en el sentido de la más precisa identificación, dentro del régimen básico de las Administraciones públicas, de lo específico del régimen de la local. Y ello, en los términos siguientes:

1. ${ }^{\circ} \mathrm{Al}$ amparo siempre del título expresado en el artículo 149.1.18 CE, el legislador estatal básico tiene dos cometidos a la hora de la continuación, en sede del desarrollo constitucional, de la organización territorial del Estado: a) la concreción de la autonomía local en tanto que garan- 
tía institucional y principio de la distribución territorial del poder público administrativo constituido (cometido éste, en el que ha de traducir el régimen jurídico básico específico de la Administración local o referido a las peculiaridades constitucionales de ésta); y b) la concreción del restante régimen jurídico básico de la Administración local en el seno del común a todas las demás Administraciones territoriales.

2. $\quad$ En el primero de dichos cometidos, el legislador básico estatal ha de cubrir, para cumplir el cometido que le está constitucionalmente asignado, el campo mínimo acotado por el núcleo primario, en cuanto definitorio del modelo territorial del Estado (que es general o común), del autogobierno de los entes locales territoriales directamente regulados por la norma fundamental, tal como dicho autogobierno viene diseñado por los artículos 137, 140 y 141 CE.

\section{Contenido mínimo de unas eventuales nuevas bases del régimen local}

A la luz de estos preceptos constitucionales (y dejando fuera todo lo referente a la Hacienda local), cabe entonces identificar y enumerar los contenidos mínimos de una eventual futura Ley básica del gobierno y la administración local, en calidad de régimen básico específico de la Administración local, del modo siguiente:

\section{1. Ámbito subjetivo y objetivo del régimen local básico}

1. Extensión sólo a las entidades territoriales objeto de garantía institucional en calidad de elementos necesarios de la Administración local en cuanto instancia territorial basal del Estado constituido: el Municipio y la Provincia (así resulta del artículo 137, en relación con los artículos 140 y 141 CE), sin perjuicio de las referencias mínimas indispensables, por conexión, a las restantes entidades locales posibles y no integrantes del modelo territorial general del Estado en amplio sentido, para asegurar que su coexistencia con aquéllas no produce en ningún caso lesión o desnaturalización del estatuto básico de las necesarias.

2. Comprensión obligada - dados los términos del artículo $137 \mathrm{CE}$ (gestión, con autonomía, de los círculos territoriales de interés correspondientes, lo que debe traducirse en el pertinente elenco de competencias como condición inexcusable para la realidad de las pertinentes instituciones de autogobierno)de la organización y las competencias de las entidades locales necesarias. Doble dimensión del régimen local básico que no es sino trasunto de la doble función de la autonomía local como garantía institucional y principio de la distribución del poder público administrativo constituido. 


\subsection{Organización de Municipios y Provincias}

1. Comprensión obligada, dada su recíproca imbricación, de la doble dimensión estática o constructiva (organización en sentido estricto o estructura) y dinámica o de funcionamiento interno (organización en sentido amplio), tanto más cuanto que de la segunda depende la igualdad y efectividad esenciales del derecho fundamental de los ciudadanos - en su calidad de vecinos y, por tanto, miembros de la corporación territorial) a participar en los asuntos públicos directamente o por medio de representantes (en primer o segundo grado); dependencia que, además, actualiza la competencia estatal transversal para regular las condiciones básicas que garanticen la igualdad en el ejercicio de los derechos y el cumplimiento de los deberes constitucionales ex art. 149.1.1 CE).

2. En punto a la organización en sentido estricto, inclusión de los siguientes aspectos:

- Caracterización, ex arts. 140 y 141 CE (en relación con la CEAL), de: i) los Municipios sobre la base de los siguientes elementos: entidades básicas de la organización territorial del Estado y, en tal condición, Administraciones públicas territoriales con plena personalidad jurídica propia; naturaleza corporativa e integración por los residentes (vecinos) en el correspondiente término; y gestión por Ayuntamientos, bajo la propia responsabilidad (es decir, con autonomía) y en el marco de la Ley, de los intereses públicos que afectan a la colectividad que institucionalizan; y ii) de la Provincia a partir de los siguientes elementos: entidad local determinada por la agrupación forzosa de los Municipios de la provincia y, en tal condición, Administración pública territorial con personalidad jurídica propia; naturaleza corporativa de segundo grado e integrada por los Municipios agrupados en ella; y gestión por Diputaciones u otras Corporaciones de carácter representativo (de los Municipios), bajo la propia responsabilidad (es decir, con autonomía) y en el marco de la Ley, de los asuntos públicos derivados de la agrupación municipal.

- Determinación de los atributos correspondientes a la caracterización anterior, en tanto que ésta se refiere a poderes públicos-ordenamientos territoriales singulares, comprendiendo (para garantía de la integridad y funcionalidad de tales poderes-ordenamientos): i) el reconocimiento, como fundamental, de la potestad de autoorganización (como inherente, según la doctrina constitucional, a toda autonomía), con posibilidad - a título de garantía del núcleo del contenido esencial de la garantía institucional de aquélla y delimitación negativa del espacio competencial de desarrollo autonómico- de un «techo» mínimo de la autoorganización traspasado el cual no cabe hablar ya de verdadero autogobierno; ii) la clarificación de que la gestión local comprende la posibilidad de la toma de decisiones bajo la propia responsabilidad tanto normativas, como de caso concreto; y iii) la atribución de las potestades formales (programación, presupuesta- 
ción, planificación, expropiación, sanción, etc...) y las prerrogativas (presunción de legitimidad, ejecutividad, ejecución forzosa, investigación/ deslinde y recuperación de oficio de los bienes propios y prerrogativas y prelación crediticias) propias de toda Administración territorial.

- Prohibición, como complemento de dicha caracterización y garantía respecto del marco legal del autogobierno, de Leyes singulares que excepcionen, para Municipios o Provincias o asuntos concretos y en detrimento del autogobierno local, el estatuto general - estatal o autonómico - de éste.

- Determinación de los elementos indispensables de la organización (ex arts. 140 y $141 \mathrm{CE}$ ): a) municipal: término y denominación; población (padrón, estatuto - derechos y deberes - del vecino); umbral de la gestión directa (Concejo abierto) y la mediada por representantes (Ayuntamientos); órganos directos (en el caso de Concejo abierto) y representativos (en el caso de Ayuntamiento) de gobierno y administración mínimos y fundamentales en función de la previsión constitucional de la integración de los Ayuntamientos por el Alcalde y los Concejales, con establecimiento a favor de éstos de la reserva de las decisiones esenciales que asegure su función directiva y su responsabilidad última universales de la gestión municipal; determinación de la integración de los órganos de gobierno y administración mínimos tanto en el caso del Concejo abierto, como en el de los Ayuntamientos, con exigencia, para estos últimos, del carácter electivo en los términos del artículo $140 \mathrm{CE}$ (con opción por i) la elección directa o indirecta - por los Concejales - del Alcalde; ii) la fijación de la primera para determinado tipo de Municipios (por tamaño, por ejemplo) y de la segunda para el resto, o, por el contrario, iii) permisión de ambas opciones, defiriendo al legislador autonómico o, en su caso, a la autoorganización municipal la decisión entre una u otra); aseguramiento y reparto de funciones entre dichos órganos (con posible diferenciación, según el sistema de elección del Alcalde), así como reglas fundamentales para la resolución de conflictos entre ellos, como exigencia de la definición del modelo de autogobierno; y b) provincial: demarcación provincial, miembros (Municipios) de la corporación (estatuto de los mismos); órganos mínimos y fundamentales de la Diputación o Corporación alternativa en función de la previsión constitucional de la agrupación forzosa de los Municipios; determinación del carácter representativo de dichos órganos mínimos y de los términos de su integración; y distribución básica de funciones entre tales órganos como condición de la definición del modelo de autogobierno.

- Referencias indispensables a la organización (creación y regulación) de otros entes locales no garantizados constitucionalmente de modo directo (especialmente de los previstos por el artículo $141 \mathrm{CE}$ ) para la preservación de la integridad y efectividad del estatuto del gobierno y administración de Municipios y Provincias. 
3. En punto a la organización en amplio sentido (funcionamiento), inclusión de los siguientes aspectos:

- Determinación del estatuto (derechos y deberes) de los Concejales, en tanto que representantes, en la Corporación, de los vecinos y, por tanto, figuras mediadoras en la participación ciudadana en los asuntos públicos administrativos gestionados por el Municipio, comprensivo de todos los aspectos indispensables para asegurar el correcto y eficaz desempeño del mandato recibido de la ciudadanía y de sus funciones propias. Debiendo comprender el estatuto, como condición mínima de salvaguarda del pluralismo propio del carácter democrático de la organización, la posición y la actuación de los grupos en que se integren políticamente los Concejales.

- Regulación en lo fundamental del derecho de participación directa de los vecinos (asistencia a sesiones de órganos colegiados; derecho de acceso a y consulta de los registros y archivos; consultas y referendos, etc...), en calidad de condiciones básicas para el ejercicio de igualdad del derecho fundamental de participación en los asuntos públicos.

- Peculiaridades, por razón de las características específicas de los entes locales necesarios, del régimen de funcionamiento de los órganos mínimos definitorios del sistema de gobierno, especialmente de los de carácter colegiado (por ej. la consistente en la posibilidad, no obstante estar ejercitándose competencias de naturaleza administrativa, de la abstención en la votación y la impugnación por los que hubieran votado en contra de los acuerdos adoptados), así como, en su caso, del régimen de aprobación de los acuerdos y de impugnación de éstos (desde luego, por razón del título competencial relativo a la legislación procesal, del régimen de ejercicio de acciones por las entidades locales necesarias).

4. En punto a relaciones entre la Administración local y las restantes Administraciones, especialmente las territoriales (organización en sentido amplio) y en calidad tanto de garantía frente a controles gubernativos o administrativos indebidos del autogobierno local (incluyendo desde luego y especialmente, como prohibida, la técnica de la subrogación en competencias locales), como de exigencia de la definición del modelo general de la organización territorial del Estado (especialmente del principio de lealtad institucional y los de él derivados), así como en virtud, en su caso, del título competencial relativo a legislación procesal:

- Peculiaridades, por razón de las características de la Administración local, del juego de los principios de colaboración, cooperación y coordinación, con interdicción, en todo caso, de cualesquiera técnicas que lesionen la capacidad de decisión bajo la propia responsabilidad y de autoorganización. Sin perjuicio de la regulación básica que de esta 
cuestión se contenga en el régimen básico común de las Administraciones públicas.

- Peculiaridades del régimen de impugnación de los actos y acuerdos locales, sin perjuicio de la regulación básica que de esta cuestión se contenga en el régimen básico común de las Administraciones públicas.

5. Por lo que hace a los medios personales (empleados públicos) y materiales (bienes), también pertenecientes (pero de forma más indirecta) a la organización en sentido amplio, pero integrantes de otras materias contempladas por el sistema constitucional de distribución de competencias (en especial los enumerados en el artículo 149.1.18 CE, pero también el apdo. 8 del mismo precepto constitucional), debe entenderse que priman sobre el de régimen específico local los títulos competencias mas especializados y su regulación quedar remitida a la legislación dictada al amparo de éstos.

No obstante, también aquí debe afirmarse la prevalencia del título régimen básico local por lo que respecta a las peculiaridades de los entes locales necesarios.

En materia de bienes existen peculiaridades merecedoras de tratamiento básico, desde luego las derivadas de la historia y con relevancia incluso constitucional (bienes comunales, bienes en mano común), especialmente por lo que hace a la propiedad y al aprovechamiento de los bienes.

En lo que hace al empleo público, las dos peculiaridades más relevantes a las que debería atender desde luego dicho régimen (en su caso, a la vista del actual estatuto básico del empleado público) son:

- El estatuto de las funciones públicas (y de sus servidores) específicas del mundo local, que se concretan tradicionalmente en las figuras de los Secretarios Generales (control jurídico interno y fe pública local) e Interventores (control y fiscalización internos del gasto y de la ejecución presupuestaria).

- El espacio decisional autónomo reservado (como umbral mínimo del autogobierno - fundamental a efectos de la autoorganización - a respetar por toda legislación, especialmente la autonómica de régimen local) a los entes locales necesarios en desarrollo del estatuto básico del empleado público.

\subsection{Competencias municipales y provinciales}

El específico régimen básico local debe necesariamente extenderse, según ya se ha razonado, a las competencias de municipios y provincias. Procede, sin embargo, abordarlo por separado y en relación con el texto del frustrado (en la 
pasada legislatura) borrador de Ley básica del gobierno y la administración local.

No obstante, conviene adelantar en este lugar que, en este punto, el cumplimiento de la función constitucional de concreción general que le corresponde en sede de desarrollo constitucional, impone a la legislación básica estatal la inclusión de una regulación del régimen general de las competencias de los Municipios y las Provincias en términos equivalentes a cómo lo hacen en la actualidad los artículos 7, 8 y 59 de la vigente Ley básica 7/1985, de 2 de abril. La finalidad de esta regulación, absolutamente indispensable para asegurar la integridad del autogobierno, no sería otra que evitar la desnaturalización del autogobierno local, con defraudación del principio de descentralización administrativa (parte componente del modelo general del poder público administrativo), a través de la libre configuración, caso a caso y sector o sector, por la legislación administrativa de los términos de la atribución y de ejercicio de las competencias locales.

\subsection{Régimen de la actividad ad extra de los entes locales necesarios}

Con carácter general, es muy discutible que todo lo que desborda claramente el ámbito interno de la Administración determinada por la Constitución y, por conexión, el sistema fundamental de relaciones de aquélla con las restantes Administraciones públicas de las instancias territoriales superiores pueda tener acogida en el específico régimen básico local. Al día de hoy esto es claro no ya a la vista de las últimas reformas estatutarias, sino, sobre todo, por la evolución de:

- La capacidad de gestión del mundo local, que inclina a integrar en mayor medida la materia, por ejemplo, de las formas de gestión de los servicios, en la potestad de autoorganización en el marco de la legislación general, especialmente de la de contratación.

- La doctrina constitucional acerca del carácter accesorio (respecto de las materias objeto de títulos competenciales específicos) de las cuestiones tales como las relativas al procedimiento y las sanciones.

- La integración europea y la realidad (progresivamente de mayor entidad y extensión) de que importantes sectores de la acción administrativa (así, la contratación, pero también el procedimiento) son objeto de configuración ya desde el escalón comunitario-europeo, lo que lleva a la conveniencia de dejar abierto el ordenamiento local para la más fácil recepción de los cambios normativos en los niveles superiores.

- La legislación sectorial y la regulación que hace de su objeto en cada caso. 
La inclusión, pues, en el régimen básico local de alguna prescripción sobre estos extremos sólo sería posible en la medida en que fuera estrictamente indispensable para la definición mínima común del autogobierno local como elemento definitorio del modelo general de organización territorial del Estado.

Sólo dos cuestiones deberían o, en su caso, podrían formar parte, en este ámbito «externo»- del régimen básico local: i) de un lado - y ésta es la más clara-, la sin duda importante (para la posición de la Administración local garantizada constitucionalmente en la estructura del Estado) determinación de la facultad municipal y, en su caso, provincial, para el ejercicio de la iniciativa económica (al servicio de los intereses locales y en beneficio de las colectividades correspondientes) en los términos del artículo 128.2 CE; y, de otro lado -y ésta más cuestionable o, cuando menos, dudosa, pero merecedora de consideración - identificable bajo la denominación tradicional de «municipalización» $y$, en su caso, «provincialización» de servicios».

\section{Alcance de unas eventuales nuevas bases del régimen local}

Las anteriores consideraciones se mueven estrictamente en el plano de la identificación de lo que debería ser objeto de regulación (como mínimo) por un futuro régimen básico local, por lo que nada dicen sobre el alcance de dicha regulación. En la medida en que «lo básico» en esta materia:

a) resulta de imposible determinación con carácter general al depender de las características y trascendencia del objeto en cada caso regulado para el principio y la garantía institucional de la autonomía local como elemento del modelo general de Estado; y

b) presenta asimismo una alta dependencia de opciones políticas,

en esta sede únicamente puede decirse que siempre y en todo caso la regulación básica estatal debe tener sólo el alcance necesario o indispensable, pero, al mismo tiempo, todo el que sea preciso para, como concreción de los artículos 137,140 y $141 \mathrm{CE}$ y, por tanto del principio y la garantía institucional de la autonomía local, la definición completa - a título de mínimo común denominador - de la Administración local integrada por Municipios y Provincias como pieza basal del modelo territorial del Estado constituido por la norma fundamental. 
